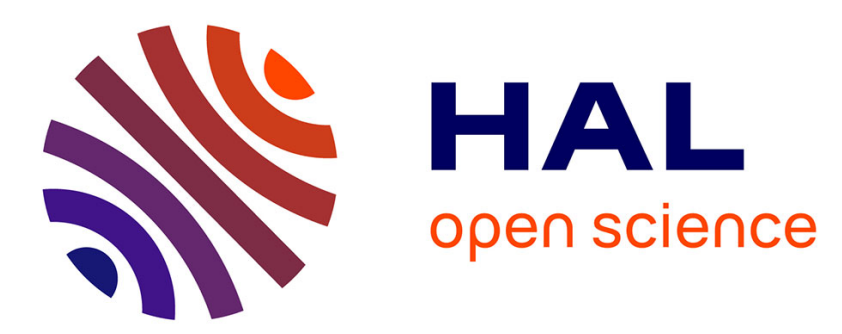

\title{
Numerical modelling of desiccation cracking of clayey soil using a cohesive fracture method
} Thi Dong Vo, Amade Pouya, Sahar Hemmati, Anh Minh A.M. Tang

\section{To cite this version:}

Thi Dong Vo, Amade Pouya, Sahar Hemmati, Anh Minh A.M. Tang. Numerical modelling of desiccation cracking of clayey soil using a cohesive fracture method. Computers and Geotechnics, 2017, 85, pp.15-27. 10.1016/j.compgeo.2016.12.010 . hal-01515964

\section{HAL Id: hal-01515964 \\ https://hal-enpc.archives-ouvertes.fr/hal-01515964}

Submitted on 10 May 2017

HAL is a multi-disciplinary open access archive for the deposit and dissemination of scientific research documents, whether they are published or not. The documents may come from teaching and research institutions in France or abroad, or from public or private research centers.
L'archive ouverte pluridisciplinaire HAL, est destinée au dépôt et à la diffusion de documents scientifiques de niveau recherche, publiés ou non, émanant des établissements d'enseignement et de recherche français ou étrangers, des laboratoires publics ou privés. 


\section{Numerical modelling of desiccation cracking of clayey soil using a cohesive}

\section{2 fracture method}

3

4 Thi Dong Vo ${ }^{1,2}$, Amade Pouya ${ }^{2}$, Sahar Hemmati ${ }^{1}$ and Anh Minh Tang ${ }^{2}$

$5 \quad{ }^{1}$ Université Paris Est, IFSTTAR GERS/SRO, Marne-la-Vallée, France

$6 \quad{ }^{2}$ Université Paris Est, Laboratoire Navier (UMR8205), Marne-la-Vallée, France

7

8 Corresponding author:

9 Anh Minh TANG

10 Ecole des Ponts ParisTech

11 6-8 avenue Blaise Pascal, Cité Descartes, Champs sur Marne

1277455 Marne-la-Vallée, Cedex 2, France

13 Phone: +33164153563

14 Email: anhminh.tang@enpc.fr

15

16

17

18

19

20

21

22

23

24

25

26

27

28 
29 Abstract. This paper presents a numerical study on the desiccation cracking process of clayey 30 soil. The initiation and propagation of cracks were investigated using finite element code, 31 including the damage-elastic cohesive fracture law to describe the behaviour of cracks. The coupling between the hydraulic behaviour (moisture transfer in the soil matrix and in the cracks) and the mechanical behaviour (volume change of the soil matrix and development of cracks) were also considered. The results of a laboratory experiment performed on clay soil, taken from a literature review, were used to evaluate the numerical modelling. The results show that the code can reproduce the main trends observed in the experiment (e.g., shrinkage related to drying, crack development). In addition, the numerical simulation enables the identification of other phenomena, such as the evolution of suction and stress related to drying and the development of a single crack. These phenomena are difficult to observe experimentally.

Key words: suction, evaporation, desiccation cracking, cohesive fracture, damage

(1)




\section{Introduction}

Desiccation cracking is a common phenomenon in soils and rocks. It involves a gradual moisture content reduction induced by evaporation from a geomaterial surface. This reduction in moisture content is accompanied by the invasion of air into the soil pores, increases in suction and the effective stress, and soil shrinkage. Shrinkage due to desiccation from the soil surface in restrained conditions (by frictional boundary conditions, concentration of stress or heterogeneity of soil) causes an increase in tensile stress, which induces the formation of crack networks when the stress reaches the tensile strength ([1]-[6]).

Due to the hydro-mechanical nature of the formation and propagation of desiccation cracking, this process influences various soil properties. On one hand, cracks change the permeability of soil from the hydraulic point of view. On the other hand, desiccation cracking changes the soil compressibility and decreases the mechanical strength, which could be one of the reasons for the instability of earth slopes ([7]-[9]).

The problem of desiccation cracking in soil has been studied using both experimental and theoretical approaches. Laboratory experimental studies ([5][10][11][12]) have mainly focused on the behaviour of clayey soil when drying specimens from a saturated state. The results demonstrate the effect of specimen dimensions, boundary conditions, soil properties, and drying conditions on the formation, propagation process and morphology of the crack network. Desiccation cracking has also been observed in situ ([13][14]), where the characteristic geometry of cracks, such as depth, thickness, density, spacing, and aperture, under the actual drying conditions were investigated. The results show that the onset of cracking depends on the mineralogy of the soil, the climatic conditions (temperature, relative humidity, rainfall), and the canopy. Following Li \& Zhang ([13]), crack development can be described in three stages: initial, primary, and steady state. In the initial stage, few cracks develop with gradually decreasing water content. When the water content reaches a critical value for crack initiation, 
cracks being to develop quickly, corresponding to the start of the primary stage. As the water content approaches the shrinkage limit of the soil, cracks develop slowly and reach a steady state.

Using numerical methods, the initiation and the propagation of cracks have been studied based on the theory of linear elastic fracture mechanics (LEFM), discrete element method (DEM), and finite elements method (FEM) with or without cohesive fracture and interface elements.

The propagation of cracks in solids has been studied using LEFM [15] to explain the magnitude of the depth and the spacing between desiccation cracks. This theory has been extended to unsaturated soil $([2][16][17])$ to predict the optimal depth of cracks, which is a function of the suction profile and various soil properties (e.g., tensile strength, elastic modulus, Poisson's ratio, density). Konrad \& Ayad [18] used LEFM to analyse the propagation of desiccation cracks of clays under evaporation. They used the principle of the effective stress distribution [3] to take into account the distribution of stress in soil and proposed the concept of virtual stress superposition to predict the average spacing between primary cracks. LEFM considers the propagation of only one individual crack and neglects the interaction between various cracks. In addition, LEFM assumes linear elastic soil behaviour; the nonlinearity that may be present in desiccation is thus ignored.

DEM, which considers the soil as an assemblage of discrete elements, has good potential for the simulation of desiccation cracking and was used in previous studies ([19]-[22]). Most active clay particles gather in elementary small structures called aggregates, which in turn gather in larger aggregates at various scales ([23][24]). In DEM, the clay soil is represented as an assemblage of aggregates linked by bonds, and the aggregates are simplified as spherical grains or other geometries [21]. The drying shrinkage kinetics of clay aggregates can be simulated by applying an explicit relationship between the size of the grains and the drying duration (or the water content). As the soil dries, the contact stiffness and tensile strength of the 
aggregates increase with increasing suction. Crack initiation corresponds to the irreversible breakage of this bond when the magnitude of the traction (or shear) force exceeds the normal

103 (or shear) contact bond strength. In addition, the non-linear behaviour of soil can be simulated

104 by introducing the dependences of the soil properties on suction ([19][21][22]). Simulations

105 have enabled the investigation of the effects of the soil sample dimensions, the interface 106 between soil/mould, and soil shrinkage parameters on the development of desiccation cracks.

107 More recently, Hirobe \& Oguni [25] proposed a model that uses FEM to simulate hydraulic 108 diffusion and PDS-FEM (particle discretisation scheme finite element method) to solve the 109 mechanical problem of the formation of cracks. In this model, the elasticity and fracturing 110 behaviour are modelled using the discretisation method, which uses a pair of conjugate 111 geometries (Voronoi and Delaunay tessellations) to estimate the displacement and strain fields.

112 A fracture propagates along the Voronoi cell boundaries as hydro-mechanical stress evolves 113 and exceeds the prescribed material strength. This method was used to reproduce the 114 morphology of the crack network and the evolution of the desiccation process. The principle of 115 this work is similar to that of Asahina et al. [26]. Both demonstrated the influence of the 116 specimen's thickness on the spacing of the formed cracks. Despite its efficiency to simulate 117 desiccation cracks, DEM is considered more pertinent for the specimen scale than the structure 118 scale.

119 Soil desiccation has been studied using FEM in previous research ([27]-[29]), but the 120 development of cracks (which involves discontinuity in the medium) was not considered. For 121 this reason, cohesive fracture and interface elements are usually introduced in FEM code to 122 simulate the formation and propagation of cracks during desiccation. In the work of Sanchez et 123 al. [30], joint elements were embedded like interface elements in the boundary of tetrahedral 124 solid elements; the cracks propagated along the boundary of these solid elements. In this 125 numerical analysis, the effect of evaporation was introduced as the volume shrinkage of solid 
elements, and the simulation could be observed as purely mechanical. The prime interest of

127 this work was not to precisely reproduce the experimental observations but to determine the

128 ability of the proposed numerical technique to qualitatively capture the main trends and the

129 crack morphologies observed for different shapes, thicknesses and desiccation conditions.

130 Amarasiri \& Kodikara [31] used cohesive cracks with a softening law that evolves during

131 desiccation when a crack is partially open. The model reproduced the number of cracks

132 developed with the moisture content evolution during a desiccation test but the desiccation

133 process with hydro-mechanical coupling was not considered.

134 In the present work, a hydro-mechanical model was developed to simulate the desiccation

135 cracking of clayey soil using a cohesive fracture method. The damage-elastic behaviour of

136 cohesive fracture [32] was used to model the initiation and propagation of cracks. The FEM

137 code POROFIS [33], for POROus FISsured media, was used to simulate the laboratory

138 desiccation tests reported by Sanchez et al. [11]. The results enabled the investigation of the

139 evolution of the stress, strain and hydric state (suction, degree of saturation) at different

140 locations in the soil specimen and the development of cracks during desiccation.

\section{Governing equations}

142 This section briefly presents the governing equations of hydraulic and mechanical problems;

143 more details can be found in [32]-[34]. In the present model, soil is represented as a

144 homogenous porous medium containing a family of cohesive cracks. For the hydraulic

145 problem, the body can be subjected to pressure or flux boundary conditions. For the

146 mechanical problem, the body can be subjected to stress or displacement applied on its surface.

147 Other volumetric forces and gravity effects are not considered for this problem. The flow and

148 displacement fields in the body have to satisfy theses boundary conditions and the constitutive

149 equations detailed below. 


\subsection{Cohesive crack representation}

151 In the finite elements method enriched by joint elements (JFEM) used here, the cohesive crack

152 elements are represented by 4-node interface elements introduced by Goodman (1976) [35] for

153 modelling rock joints. The joint elements are placed in the mesh on predetermined paths

154 corresponding to potential crack propagation. For the mechanical problem, it is necessary to

155 split the nodes on discontinuity lines and create joint elements to allow displacement

156 discontinuities across fractures. However, in the hydraulic problem, at least for the fractures

157 with infinite transverse conductivity considered here, and so with continuous pressure across

158 the fracture, there is no need to split the nodes because the pressure has the same value on the

159 two sides of the fracture. The specific mesh for this purpose is prepared using commercial tools

160 (GID and DISROC) that are dedicated to meshing fractured media.

161 One of the limitations of the cohesive crack method is that the crack locations and pathways

162 need to be predefined. However, this limitation can be addressed by using a multiple unbiased

163 potential crack with a great density to minimise the spacing between cracks. This approach is

164 chosen in the current work.

165 In this model, cohesive cracks are simulated as elements of zero thickness with a very small

166 normal hydraulic conductivity and high stiffness at the beginning. For the mechanical

167 behaviour of joint elements, the cohesive fracture law [32] is applied. A damage variable $D$ is

168 added to represent the process of damage through a decrease in the crack stiffness and the

169 evolution of the yield surface. Under the effect of evaporation, the tensile stress increases with

170 suction, corresponding to the increase in the normal stress of cohesive cracks. The initiation of

171 cracks can be considered as the breakage of bonds through the degradation of the crack

172 stiffness when the tensile stress reaches the tensile strength. 
174

175 The flow in the soil around cracks is governed by Darcy's law and satisfies the mass 176 conservation condition. To establish hydraulic diffusion, the fluid mass $m_{f}$ is calculated in unit volume:

$$
m_{f}=\rho \phi S,
$$

where $\phi$ is the porosity, $\rho$ is the fluid density and $S$ is the degree of saturation of the medium. For a saturated medium, $S=1$, and the pore pressure $p$ takes positive values.

The soil suction $s$ is the difference between the gas (vapor and air) pressure $p_{g}$ and the fluid pressure $p$ in the pore space:

$$
s=p_{g}-p
$$

In the present work, gas pressure is zero. This means that in the unsaturated state, $s=-p$. By extending the pressure values to the negative domain, it is possible to represent, by a unique variable $p$, the pressure in the saturated state $p \geq 0$ and the suction in the unsaturated condition $p<0$. Upon drying, the degree of saturation $S$ is related to suction through the water retention curve, expressed by the function $S=f(p)$, based on the Van Genuchten model [36]:

$$
\frac{S-S_{r e s}}{1-S_{\text {res }}}=\frac{1}{\left(1+(\alpha p)^{n}\right)^{m}}
$$

191 where $S_{\text {res }}$ is residual degree of saturation and $\alpha, n$ and $m$ are soil parameters.

192 The equation to determine the flow in the soil matrix with an assumption of incompressible

193 fluid can be then written as follows [37,33]:

$$
\operatorname{div}\left(\frac{k}{\rho g} \nabla p\right)=C_{M} \frac{\partial p}{\partial t}+r
$$


195 with $C_{M}=S\left(\frac{1}{N}+\frac{\phi S^{\prime}}{S}\right), r=S \frac{\partial \varepsilon_{v}}{\partial t}, k$ is the soil hydraulic conductivity, $g$ is acceleration

196 due to gravity, $N$ is the Biot modulus, $S$ is the derivative $d S / d p$ calculated from the water

197 retention curve, and $\varepsilon_{v}$ is the volumetric deformation. The hydraulic conductivity $k$ decreases

198 during drying and is simulated as follows:

$$
k=k_{s}\left(\frac{S-S_{r e s}}{1-S_{r e s}}\right)^{3}
$$

where $k_{s}$ represents the soil hydraulic conductivity in the saturated state.

201 For cracks, the transverse conductivity (between the two crack walls) is considered as infinite 202 in the model, which implies that there is no pressure difference between two opposite walls of 203 the crack, i.e., the pressure has the same value on both faces. It could also be represented by 204 only one value of $p$ at a given point along the crack line. The flow in the cracks is governed 205 by the cubic law with the isotropic tangent conductivity of cracks (parallel to crack walls) 206 denoted by $c$, which can be related to crack opening $e$ and fluid viscosity $\mu$ through the 207 following relation [38]:

$$
c=\frac{e^{3}}{12 \mu}
$$

209 The equation to calculate the pressure for every location $\underline{s}$ along the crack surface can be then 210 written as:

$$
\nabla_{s} \cdot\left(c \partial_{s} p\right)=r^{m f}+r^{f}
$$

212 where $r^{m f}=\|\underline{v}\| \cdot \underline{n}$ and $r^{f}=\frac{\partial e}{\partial t}$.

213 In this equation, $\nabla_{s} .()$ designates the divergence in the crack. The velocity $\underline{v}$ must be related 214 to the flow in the matrix and can be discontinuous, with values $\underline{v}^{+}$and $\underline{v}^{-}$for the two faces of 
215 the crack. The term $\|\underline{v}\|=\left[\underline{v}^{+}-\underline{v}^{-}\right]$represents the velocity discontinuity or the jump across 216 the crack surface, which expresses the fluid mass exchange between the crack and the 217 surrounding matrix, and $\underline{n}$ is the unit vector normal to the fracture surface. In Eq. (7), the 218 source term $r^{f}$ represents hydro-mechanical coupling and $r^{m f}$ represents mass exchange 219 between the matrix and the crack.

\subsection{Mechanical behaviour}

221 The mechanical behaviour of the soil matrix is formulated in terms of the effective stresses 222 while the failure criterion of the cohesive cracks is based on the total stress. If the cracks are 223 considered as very large pores, the suction in these pores is negligible, so it is reasonable to 224 model their failure in terms of the total stress. This is in agreement with experimental 225 observations ([19][22]), which show a small effect of the water content on the tensile strength 226 of soils. This small effect is neglected in the present work. At the interface between the matrix 227 element and the joint element, the continuity of the total stress is ensured.

The soil matrix is assumed to be an isotropic elastic linear material, and the relation between the effective stress and strain is expressed by the following equation:

$$
\underline{\underline{\sigma}}=C: \underline{\underline{\varepsilon}}-S p \underline{\underline{\delta}}
$$

231 where $\sigma$ is the total stress, $C$ is the elasticity tensor, $\varepsilon$ is the strain tensor and $\underline{\underline{\delta}}$ is the 232 identity matrix.

233 The elastic damage of the cohesive crack law is applied using the following equation:

$$
\underline{\sigma}=(1-D) \underline{\underline{R}} \underline{u}-b_{f} p \underline{n},
$$

where $\underline{\sigma}$ is the stress vector on the matrix/crack interface surface, $\underline{n}$ is the normal unit vector 236 on this surface, $\underline{u}$ is the displacement discontinuity through this surface, $\underline{\underline{R}}$ is the crack 237 stiffness tensor, $b_{f}$ is Biot's coefficient of cracks and $D$ is the damage variable. The 
coefficient $b_{f}$ is related to the ratio of the contact surfaces between the two walls of the crack

239 to the total crack surface. A value of $b_{f}=1$ means the whole pressure in the crack is applied as

240 mechanical action on the walls, which corresponds to the case of a totally damaged crack,

241 without a bridge between the walls. When there is no damage $(\mathrm{D}=0), b_{f}=b_{0}$ should be very

242 small. $b_{f}$ increases with $D$ and reaches 1 for $D=1$. We express this relationship using the

243 following law:

$$
b_{f}=b_{0}+\left(1-b_{0}\right) D
$$

245 The crack aperture $(e)$ changes with the deformation from the initial value $e_{0}$ to:

$$
e=e_{0}+u_{n}
$$

where $u_{n}$ is the normal component of $u$. The evolution of the damage variable $D$ affects both

the crack stiffness and the yield surface. The yield criterion is defined by a hyperbolic surface

249 in the stress space, which corresponds to the following expression [32]:

$$
F(\sigma, D)=\tau^{2}-\sigma_{n}^{2} \tan ^{2} \varphi+2 g(D) \sigma_{c} \sigma_{n}-g^{2}(D) \mathrm{C}^{2},
$$

251 with: $\sigma_{c}=\frac{C_{\mathrm{coh}}^{2}+\sigma_{R}^{2} \tan ^{2} \varphi}{2 \sigma_{R}}$,

252 where $\tau ; \sigma_{n}$ are the tangential and normal stresses of the joint, $C_{\text {coh }}$ is the cohesion of the 253 intact (undamaged) joint, $\varphi$ is the friction angle, $\sigma_{R}$ is the tensile strength of the intact joint 254 and $\beta$ is a coefficient representing the material's ductility.

255 The function $g(D)$ in Eq. (12) is defined such that the tensile strength, which is $\sigma_{R}$ for the intact 256 interface element, tends to zero for the totally damaged element: $g(D)=(1-D)(1-\beta \ln (1-D))$

258 The damage evolution law in the cohesive fracture model [32] is given by the following 259 relation: 


$$
\begin{cases}D=0 & \text { for } u_{n}<u_{0} \\ D=1-e^{-\frac{\left(u_{n}-u_{0}\right)}{\beta u_{0}}} & \text { for } u_{n} \geq u_{0}\end{cases}
$$

261 where $u_{0}=\frac{\sigma_{R}}{R_{n n}}$ is the elastic displacement limit, and $R_{n n}$ is the normal component of the

262 joint stiffness.

263 2.4. Hydro-mechanical coupling

264 The coupling between the mechanical and the hydraulic problems is performed through 265 sequential resolution of the two problems and the interactions between them. The schematic 266 view, shown in Fig. 1, represents the hydro-mechanical coupling for desiccation cracking 267 phenomena as resolved by POROFIS. For each time increment, the hydraulic problem is 268 calculated by solving Eq. (4) and Eq. (7). The outputs correspond to the soil suction, degree of 269 saturation and hydraulic conductivity of soil. These values are then used as inputs for the 270 mechanical problem. For the matrix, hydro-mechanical coupling (Eq. (8)) allows updating of 271 the effective stress in the soil matrix. Numerically, this coupling is performed by introducing 272 the term "free deformation", denoted by $\varepsilon^{L}$ in Eq. (8), under the form: $\underline{\underline{\sigma}}=C:\left(\underline{\underline{\varepsilon}}-\underline{\underline{\varepsilon}}{ }^{L}\right)$, in 273 which $\underline{\underline{\varepsilon}}^{L}=C^{-1}(\operatorname{Sp} \underline{\underline{\delta}})$. For the elastic linear isotropic model, this free deformation can be 274 calculated as a function of the elasticity modulus $E$ and the Poisson' ratio $v$ : 275 $\underline{\varepsilon}^{L}=\frac{(1-2 v)}{E} S p \underline{\underline{\delta}}$. For cracks, the fluid pressure resulting from the resolution of the hydraulic problem (Eq. (7)) is introduced in the mechanical problem (Eq. (9)) to calculate the crack opening. Reciprocally, the matrix and the crack deformation resulting from the resolution of 278 the mechanical problem are then introduced into the hydraulic problem through source term $279 r$, which is related to the volumetric strain of the matrix (Eq. (4)), and $r^{f}$, representing the crack opening evolution (Eq. (7)). In addition, the crack opening $e$ is used to update the hydraulic conductivity of the crack (Eq. (6)). This coupling implies that as soon as the crack is 
mechanically opened, its hydraulic conductivity increases quickly and potentially conducts more fluid through it.

\section{Numerical simulation}

The hydro-mechanical finite element code presented above was used to simulate the desiccation experiments reported by Sanchez et al. [11]. In this test, a $100 \mathrm{~mm}$ diameter and 13 mm thick circular plate of organic silt (30\% sand, $57 \%$ silt and $13 \%$ clay) was prepared in a slurry state and then air-dried. By using a 2D profile laser technique, various soil characteristics (e.g., volume change, water loss, and crack development) were observed during drying.

To simulate the experiments, various data related to the tested materials were collected to 292 determine the parameters used in the numerical model. Fig. 2 shows the water retention curve 293 obtained for the same soil but from a compacted specimen [39]. The degree of saturation at low suction $(0.001 \mathrm{MPa})$ is still significantly lower than 1 because of hysteresis. Therefore, the water retention curve used in the present work starts in the saturated state $(S=1)$ for the lowest suction. Various works have found that desiccation cracks initiate at soil suction close to the 297 air-entry value ([5][12]). The experimental data indicated an air-entry value of approximately $298100 \mathrm{kPa}$, so the model was fitted to the experimental data around this value. The parameters 299 selected for the water retention curve (Eq. 3) were then: $\alpha=9.81 \mathrm{MPa}^{-1}, n=1.60$, and $300 \quad m=1-1 / n=0.375$

301 The soil compressibility was estimated following the oedometer compression curve obtained 302 on the same soil but in a compacted state [40]. The volumetric strain for these data is plotted 303 versus the vertical stress for the studied soil (Fig. 3). In the present work, the soil compressibility parameters were chosen ( $E=1 \mathrm{MPa}$ and $v=0.3)$ to fit the experimental data in 
the low stress range (up to $0.3 \mathrm{MPa}$ ), which should be the range of suction corresponding to the crack development.

The hydraulic conductivity in the saturated state, $k_{s}=10^{-8} \mathrm{~m} / \mathrm{s}$, was selected following the method proposed by Mesri et al. [41], which estimates the hydraulic conductivity of finegrained soils from the void ratio, clay fraction and soil activity.

As explained above, the cohesive crack law was used to model the formation and propagation

311 of desiccation cracks. The cohesive crack parameters influence the behaviour of the model,

312 and its determination plays an important role. Several studies indicated that desiccation 313 cracking occurs mainly in mode I ([15][16][18]). Amarasiri \& Kodikara [42] presented results 314 of fracture tests performed on beams of compacted clay at various moisture contents. A bi315 linear cohesive crack law was used to model the development of bridging stress across an 316 opening crack, which progressively decreased from the tensile strength to zero as the two 317 faces separated. The properties of the cohesive crack (e.g., fracture energy, tensile strength, 318 and crack opening at which the normal cohesive stress drops to zero) were determined by 319 back-analysis. In the present work, the main parameters of a cohesive crack are: normal 320 component of the joint's stiffness tensor $\underline{\underline{R}}\left(R_{n n}\right)$, tensile strength $\sigma_{R}$, and initial crack 321 thickness $e_{0}$. The tensile strength $\sigma_{R}$ was chosen close to the air-entry value at which the 322 crack initiated, as suggested by Peron et al.[5], Tang et al. [12], and Shin \& Santamarina [43]. 323 The initial values of the normal stiffness $R_{n n}$ were set sufficiently high and that of the 324 hydraulic conductivity (related to the initial thickness $e_{0}$ ) was set sufficiently small to have 325 negligible effects on the global elasticity and permeability of the model before cracking. The 326 parameter $\beta$ corresponds to the ductility of material and can be fitted from the experimental 327 curves [44]. In this work, it was set equal to 1, which indicates that the tensile stress of the 328 fracture starts to decrease at the onset of damage. The parameters $C_{\text {coh }}$ and $\varphi$ do not affect 
mode I crack propagation, which is the case of the present work. However, these parameters

330 must satisfy the inequality $C_{\mathrm{coh}} / \tan \varphi>\sigma_{R}$ for the hyperbolic surface. Therefore, $C_{\mathrm{coh}}$ was set

331 to $C_{\text {coh }}=1.5 \sigma_{R} \tan \varphi$. Table 1 summarises the main parameters of soil and cohesive cracks 332 used in the simulation.

333 To simulate the test performed, a 2D mesh in the plane strain conditions shown in Fig. 4 was 334 used. Its width was equal to the diameter of the sample $(100 \mathrm{~mm})$, and its height was equal to 335 the initial height of the sample $(13 \mathrm{~mm})$. The experimental observation showed were 4 cracks 336 (for a typical cross section) after 24 hours of drying, and these cracks propagated vertically in 337 depth. As mentioned above, in POROFIS, a large unbiased number of cracks and pathways can 338 be introduced. Crack development is dictated by the behaviour of the model. However, in the 339 present work, to optimise the calculation cost by always ensuring adequate mesh density, 100 340 vertically oriented cohesive cracks were distributed regularly with a spacing of $d=1 \mathrm{~mm}$ in the 341 mesh (see Fig. 4).

342 For the mechanical boundary conditions, the displacements at the bottom, the right and left 343 sides were fixed, while the top of the mesh (representing the soil surface) was free to move. 344 For the hydraulic boundary conditions, no flux was allowed at the bottom, right and left sides 345 of the mesh. On the top of the mesh, homogenous flux, calculated based on the evaporation 346 rate estimated from the test, was imposed. The details of the determination of this flux are 347 given below.

348 The experimental observation of soil water evaporation ([45]-[48]) from the saturated state 349 generally indicated three main phases. The first phase corresponds to a constant evaporation 350 rate with elapsed time. In this phase, suction develops slowly, and the soil remains in a 351 saturated state. In the second phase, the evaporation rate decreases rapidly and soil suction 352 increases significantly. In the last phase, the evaporation rate reaches the residual value, which 
depends on the soil characteristics. In the present work, the evaporation rate was imposed on

354 the top of the mesh as a function of the suction calculated at the soil surface (see Fig. 5). To obtain the experimental data plotted in this figure, the relationship between the evaporation rate and the average degree of saturation of the soil specimen in the experiment was calculated from the experiment (Fig. 5a). Then, by combining this information with the water retention curve (Fig. 2), the relationship between the evaporation rate and soil suction was determined (Fig. $5 b)$. The actual evaporation rate $\left(E_{a}\right)$ was calculated based on the soil suction at the surface, as expressed below:

$$
\left\{\begin{array}{ll}
E_{a}=E_{p} & \text { if }|s| \leq\left|s_{0}\right| \\
E_{a}=E_{p} \exp \left[-\alpha\left(s-s_{0}\right)\right] & \text { if }|s|>\left|s_{0}\right|
\end{array},\right.
$$

where $E_{p}$ is the potential evaporation rate, which represents the evaporation capacity of soil under completely saturated conditions, $s$ is the actual suction at the surface, $s_{0}$ is a suction of the onset of the second phase in the evaporation process, and $\alpha$ is a curve coefficient. Wilson et al. [46] measured the actual evaporation rate using a drying column test. The evaporation rate evolution showed that the first phase had a constant evaporation rate of $8 \mathrm{~mm} /$ day. During the second phase, a slight decrease in the evaporation rate began when the sand surface became visually dry. This corresponds to a water content at the sand surface of slightly less than $2 \%$;

370 thus, the suction corresponding to this water content on the water retention curve was 371 approximately 0.5-0.6 MPa. Moreover, Wilson et al. [49] found that the actual rate of 372 evaporation began to decline when the value of the total suction exceeded approximately 3 373 MPa. This conclusion was obtained from three tested soils: clay, silt, and sand.

374 In the present work, the parameters selected by assuming the exponential form of evaporation 375 evolution (Eq. (14)) and by fitting the experimental curve were: $E_{p}=0.3 \mathrm{~mm} / \mathrm{h}, \alpha=1.857$ and $376 s_{0}=0.3 \mathrm{MPa}$. Note that $s_{0}=0.3 \mathrm{MPa}$ corresponds to an average degree of saturation $S=0.5$ 
(following the water retention curve, see Fig. 2), which corresponds to the beginning of the 378 decrease in the evaporation rate during drying (see Fig. 5a).

\section{Results}

Fig. 6a presents the morphology of the specimen during drying. This figure is plotted from the numerical results in Fig. 6b, where the distribution of horizontal displacement was equally added. The proposed model reproduced the main phases observed in the experimental test. At the beginning of the test, only settlement at the soil surface was observed without cracking (i.e., with $\mathrm{t}=3 \mathrm{~h}$ ). The two first cracks appeared close to the two lateral walls at $\mathrm{t}=4 \mathrm{~h}$. During the next $4 \mathrm{~h}$, the aperture (opening) of the cracks increased and no more cracks appeared. After $\mathrm{t}=8 \mathrm{~h}$, the crack network developed very quickly and, the cracks appeared with the same spacing of approximately 6-10 $\mathrm{mm}(\mathrm{t}=9$ and $10 \mathrm{~h})$. At $\mathrm{t}=12 \mathrm{~h}$, the specimen had 17 cracks and 100 cohesive joints were placed in the model. The evolution of suction measured at the top and at the bottom of the specimen (point $\mathrm{A}$ and point $\mathrm{B}$ in Fig. 4) is shown in Fig. 7a. The suction at these two points was similar, indicating that the suction was homogenous in the specimen during the drying test. In addition, when the first crack appeared (at $t=4 \mathrm{~h}$ ), the soil suction was approximately $0.08 \mathrm{MPa}$, smaller than the air-entry value of $0.1 \mathrm{MPa}$. The suction corresponding to the rapid development of several cracks (at $t=8-9 \mathrm{~h}$ ) was approximately 0.2

$394 \mathrm{MPa}$. After $12 \mathrm{~h}$ of drying, the soil suction reached approximately $0.3 \mathrm{MPa}$. The degree of 395 saturation calculated at these two points is also plotted in Fig. $7 b$. These values were slightly 396 lower than the average degree of saturation measured from the experiment. However, the trend 397 observed in the numerical simulation was similar to that observed from the experiment: a 398 progressive decrease in the degree of saturation during drying with the degree of saturation 399 remaining high after $12 \mathrm{~h}$ of drying. 
400 In the experimental work, the measured 2D profiles were used to calculate the three 401 components of soil shrinkage for a generic cross section: vertical displacement of the top 402 surface (settlement), lateral shrinkage (gap), and cracks (see Fig. 8). This process made it 403 possible to determine the three components of the deformation mentioned above from the 404 simulation. The results of the simulation are shown in Fig. 9. At the beginning $(t=0-3 h)$, the 405 shrinkage corresponds only to settlement. For $\mathrm{t}=3-8 \mathrm{~h}$, a gap appears, but its area remains 406 small, and the total shrinkage area is still related to settlement. From $\mathrm{t}=8 \mathrm{~h}$, cracks appear 407 quickly, and there is an abrupt increase in crack area. The increase in crack area is the main 408 cause of shrinkage area in this phase. In the experiment, drying was performed for $24 \mathrm{~h}$, while 409 in the present work, the simulation was stopped after $12 \mathrm{~h}$. Additionally, the mechanical 410 behaviour of the soil matrix is linearly elastic in this work. This assumption is reasonable only 411 when the soil strain remains small.

412 In addition to the evolution of the soil parameters, which can be experimentally observed, the 413 numerical simulation enables in depth analysis of the processes related to crack opening. Two 414 families of cracks can be identified: ( $i$ ) the two first cracks appear close to the boundary of the 415 soil specimen in contact with the rigid mould, which is defined as the lateral gap in the 416 experimental work; and (ii) the cracks develop in the middle of soil sample, which is defined as 417 "cracks" in the experimental work. The mechanisms related to the opening of these two 418 families are shown separately in Figs. 10-13.

419 Fig. 10 presents the isochrones of the normal stress, damage variable and opening of all joint 420 elements along the line of the gap on the left side $(X=1 \mathrm{~mm})$. At the beginning $(\mathrm{t}<3.505 \mathrm{~h})$, 421 the tensile stresses of these joint elements increase gradually during drying, but they remain 422 smaller than the tensile strength $\sigma_{R}=0.09 \mathrm{MPa}$; thus, no damage occurs. At $\mathrm{t}=3.505 \mathrm{~h}$, the 423 tensile stress of some joint elements on the top surface approaches the soil tensile strength (Fig. 
10a). The elastic limit is reached and the damage phase begins. At this moment, the crack remains closed at the top, no opening of the crack is observed (see Fig. 10c) and the sample shows only settlement without cracking. For the next step $(t=3.510 \mathrm{~h})$, some joint elements on the top surface $(\mathrm{Y}>12 \mathrm{~mm})$ are completely damaged, i.e., their damage variable reaches its maximum value (equal to 1) (Fig. 10b). This total damage relaxes the normal stress of these joint elements (Fig. 10a). The bridge between the two surfaces of the crack is considered to be completely broken, and the crack is opened from the surface to its extremity. Fig. $10 a$ shows that there is a stress singularity in the crack tip, which is in agreement with the LEFM [50]. For the following joint elements, normal stress continues to develop, the damage phase starts for some joint elements while others remain in the elastic phase, with damage variable equal to 0 . This process is repeated in all joint elements along the crack line, and the crack opens gradually in depth (from $\mathrm{t}=3.510 \mathrm{~h}$ to $\mathrm{t}=3.530 \mathrm{~h}$ ). The crack then propagates from the top to the bottom of the specimen in a short period (approximately $0.03 \mathrm{~h}$ ). After this propagation in depth, all joint elements in the crack line are completely damaged, their normal stress decreases to zero, and the damage variable remains 1 .

The opening of this crack $(\mathrm{X}=1 \mathrm{~mm})$ during the next step of drying (for $\mathrm{t}=4-12 \mathrm{~h}$ ) is presented in Fig. 11. The crack aperture continues to increase from $t=4 \mathrm{~h}$ to $\mathrm{t}=8 \mathrm{~h}$. After $\mathrm{t}=8$ $\mathrm{h}$, other cracks appear, and the aperture of the crack decreases suddenly from $\mathrm{t}=1.7 \mathrm{~mm}$ to 0.3 $\mathrm{mm}$ and remains at this value after 3 hours of drying.

Fig. 12 shows the isochrones of the normal stress, damage variable and opening of all joint 444 elements along the line of the crack at $X=35 \mathrm{~mm}$ (see Fig. 6). At the beginning of drying, 445 from $\mathrm{t}=1 \mathrm{~h}$ to $\mathrm{t}=8.50 \mathrm{~h}$, the tensile stress of these joint elements increases gradually while 446 drying. At $\mathrm{t}=8.50 \mathrm{~h}$, the tensile stress of the elements close to the bottom (at $\mathrm{Y}=0.6-1 \mathrm{~mm}$ ) 447 approaches the soil tensile strength $\sigma_{R}=0.09 \mathrm{MPa}$ but that of the other joint elements (with $\mathrm{Y}$ 
$>1 \mathrm{~mm}$ ) remains smaller than the tensile strength. This is the elastic phase of these joint 449 elements, and no damage occurs. At $\mathrm{t}=8.95 \mathrm{~h}$, some joint elements near the bottom of the specimen $(\mathrm{Y}<4 \mathrm{~mm})$ are completely damaged, i.e., their damage variable reaches its maximum (equal to 1) (Fig. 12b). The normal stresses of these joint elements are relaxed to zero (Fig. 12a). The total damage indicates that all the bridge or contact points between the two surfaces of the crack are completely broken, and the crack is opened from the first damaged element (very close to the bottom of the specimen) to its extremity (Fig. 12c). The process of damage is continued along the crack line, and the crack is opened gradually upward (from $\mathrm{t}=$ surface at $\mathrm{t}=9.10 \mathrm{~h}$. After this propagation along the thickness of the sample, all joint elements in the crack are completely damaged, their normal stress is relaxed to zero and the damage variable remains 1 . Fig. $12 c$ shows the evolution of the crack opening during the propagation. The crack is initiated from the element near the bottom of the sample, and there is no suction gradient in the sample (Fig. 7a). However, when the crack is detected from the surface, the crack aperture at the top is always larger than the one at the bottom. The top surface is free to move, while the bottom displacement is restrained by the prescribed boundary conditions. The 464 opening of this crack during the next step of drying (for $t=10-12 \mathrm{~h}$ ) is presented in Fig. 13. 465 After propagation to full depth, the crack aperture continues to increase until $\mathrm{t}=10 \mathrm{~h}$. Then, 466 other cracks appear near this crack (Fig. 6), and the aperture of the crack decreases suddenly 467 from $\mathrm{t}=1.6 \mathrm{~mm}$ to $0.3 \mathrm{~mm}$.

468 Fig. 14 shows the normal stress of all cohesive cracks on the top surface for $\mathrm{X}=0-50 \mathrm{~mm}$. At $\mathrm{t}$ $469=3.5 \mathrm{~h}$, the tensile stress is $0.04 \mathrm{MPa}$ for $\mathrm{X}>20 \mathrm{~mm}$, but it reaches $0.09 \mathrm{MPa}$ at $\mathrm{X}=1 \mathrm{~mm}$. At $470 \mathrm{t}=4 \mathrm{~h}$, a gap appears at $\mathrm{X}=1 \mathrm{~mm}$ (represented by a mark in the figure); the tensile stress of 471 this gap is relaxed and drops to zero. The appearance of this gap induces a reduction in the 472 tensile stress of nearby cohesive cracks. The effect of this interaction decreases with distance. 
473 From $\mathrm{t}=4 \mathrm{~h}$ to $\mathrm{t}=8 \mathrm{~h}$, no more cracks appear; thus, the tensile stress continues to increase. At

$474 \mathrm{t}=8.3 \mathrm{~h}$, a crack at $\mathrm{X}=6 \mathrm{~mm}$ appears, decreasing the tensile stress. This phenomenon is 475 repeated at $\mathrm{t}=8.5 \mathrm{~h}$ and $\mathrm{t}=8.6 \mathrm{~h}$, when cracks appear at $\mathrm{X}=11 \mathrm{~mm}$ and $\mathrm{X}=16 \mathrm{~mm}$, 476 respectively. Interaction between cracks occurs when a new crack appears, creating a stress 477 relief zone in the surface in which the stresses are reduced [18], while the prescribed boundary 478 condition at the bottom of the specimen concentrates the tensile stress in this location.

479 Fig. 15 shows the evolution of the tensile stress of the cohesive crack at $X=35 \mathrm{~mm}$ for a joint 480 element on the top surface $(\mathrm{Y}=13 \mathrm{~mm})$ and close to the bottom of the specimen $(\mathrm{Y}=0.61$ $481 \mathrm{~mm}$ ). The tensile stress of the joint element near the bottom of the specimen is higher than that 482 of the specimen on the surface. At $t=8.5 \mathrm{~h}$, the tensile stress of the joint element near the 483 bottom approaches the tensile strength $(0.09 \mathrm{MPa})$ while the tensile strength of the joint 484 element on the top surface reaches 0.06 MPa. Due to the damage cohesive crack in the model, 485 when the tensile stress reaches the soil tensile strength, the damage process occurs and the 486 crack initiates, as explained above.

\section{Discussions}

In the present work, FEM code, including hydro-mechanical coupling and cohesive crack elements, was used to simulate the desiccation cracking of soils. The matrix behaviour was assumed to be isotropic linear elastic. Elastic behaviour was also used in previous research to model desiccation cracking ([25][28]). In the present work, the elastic modulus was fitted to

492 the experimental data in the range of low stress (smaller than $0.3 \mathrm{MPa}$, see Fig. 3). After $12 \mathrm{~h}$ 493 of desiccation, the suction (and soil stress) remained in this range (see Fig. 7a).

494 Literature review ([3][15][16][18]) showed that desiccation cracking occurs essentially via 495 mode I, indicating that cracking in soils results from the development of tensile stress. As soil undergoes drying, it exhibits a suction change, which causes the inter-particle force to increase. 
An apparent cohesion term is thus created, and consequently, a tensile strength term. Kim \&

498 Hwang [51] attempted to directly relate tensile strength to the normal inter-particle force 499 calculated from micro-scale considerations. Other researchers proposed direct relations 500 between the decrease in water content and the tensile strength through experimental analysis 501 ([22][51]). Peron et al. ([5][49]) performed desiccation tests on three soils and found that 502 cracking initiates at the end of the first stage of drying. In the present work, the simulation 503 results showed that the first cracks initiate at approximately $4.0 \mathrm{~h}$, when suction equals 0.08 $504 \mathrm{MPa}$. At that moment, the evaporation rate is at its maximum value $\left(E_{p}\right)$, see Fig. 5.

505 A 2D mesh was used for the model in the present work (Fig. 4), while the experiment was 506 performed with a cylindrical specimen. The prime interest of this work is not a quantitative 507 prediction of the experimental results but a qualitative reproduction of the main trends and crack development during drying. Various experimental studies ([25][30][49][52]) show that the crack network would be different for two cases: $(i)$ for the case of a long bar (similar to the

510 model in the present work), the cracks are formed successively and perpendicular to the long 511 side of the specimen; (ii) for the case of a circular sample or a rectangular slab, the cracks can appear simultaneously or successively to create a crack network. In the experiment considered in the present work, the evolution of a typical section was analysed. A 3D mesh would then be necessary to accurately reproduce the crack pattern in this case. In the present work, only a 2D 515 mesh was used. Most of numerical studies use 2D mesh ([19][20][22][25][31]), while few 516 works consider a 3D mesh ([21][30]). Although the 3D crack pattern was not simulated in the 517 present work, the result obtained in the $2 \mathrm{D}$ study improves the understanding of shrinkage cracking mechanisms.

519 The model was able to reproduce correctly the main phases of the desiccation and the development of soil shrinkage versus elapsed time (Fig. 6,7, and 9). Initially, shrinkage is 
associated with settlement only. In the model, settlement without cracking corresponds to the

522 elastic phase of cohesive cracks, in which the tensile stress increases with drying but remains smaller than the tensile strength. The damage phase begins when the tensile stress of cohesive cracks reaches the soil tensile strength and crack initiation is observed. In the present work, the crack network appears quickly at $\mathrm{t}=8.3 \mathrm{~h}$. This time can be observed as the critical time in the cracking development process. Li et al. [13] studied desiccation crack initiation and development of the ground surface and showed that desiccation cracks develop in three stages: initial, primary and steady states. In the first stage, few cracks develop with gradually decreasing water content, and a critical suction value exists for crack initiation after which cracks appear and propagate quickly.

Kodikara \& Costa [6] presented two controlling factors in desiccation cracking. The first is the tensile stress distribution when the material is restrained against shrinkage. The tensile stress distribution depends on the boundary conditions and the material stiffness and dictates where

534 the cracks initiate. The second factor is related to the flaws and/or pores within the material, where cracks can initiate at a stress level lower than the maximum stress developed within the material. Costa \& Kodikara [55] observed that cracks could initiate even at suction of approximately $1 \mathrm{kPa}$ for a clay slurry because of the large pores. In this work, cohesive cracks 538 were placed equidistantly with the same parameters. In addition, there was no suction gradient 539 in the sample (Fig. 7a). The heterogeneity of the material properties and the flaw factors are 540 therefore neglected in this work. As a result, crack initiation depends only on the tensile stress 541 distribution, which is mainly controlled by the boundary conditions.

542 The results obtained from the present work show that the discontinuity initially develops at the 543 gaps (Fig. 6). This phenomenon can be explained by the normal stress distribution on the top 544 surface at $\mathrm{t}=3.5 \mathrm{~h}$ (see Fig. 14), where the normal stress is highest at $\mathrm{X}=1 \mathrm{~mm}$. In addition, 545 the development of the crack network in Fig. 6 shows that the cracks progressed from the two 
546 "gaps" beside the lateral boards to the middle of the sample, in agreement with the 547 observations in [11] but not a general trend [19]. In the present work, this can be explained by 548 the fact that when the gaps are created near the lateral boundaries, the stress field in the sample 549 is no longer uniform and induces new cracks that preferentially progress from the lateral 550 boundaries towards the centre of the sample. In addition, Fig. 6 shows that the crack opening 551 depends on its location. The two lateral boards are fixed, so when two faces of a crack 552 separate, the face closer to the boundary side presents a smaller displacement than the other 553 side. These cracks thus present a V shape that is not symmetric and depends on their location, 554 but the global configuration of the crack shape and location is symmetric with respect to the 555 axis of the sample.

556 The present work showed that in some conditions cracks could develop from near the bottom 557 of the specimen and propagate to reach the top surface. This can be explained in the model by 558 the combined effects of boundary conditions at the bottom that cause stress concentration at 559 these locations and the stress reduction on the top surface due to the onset of adjacent cracks 560 (Fig. 14 and 15). In this numerical model, all the joint elements are fixed to the bottom. 561 Therefore, the crack aperture cannot be observed from the bottom, similar to the observations 562 in a previous experiment ([11]). Weinberger [56] studied the initiation and growth of cracks 563 during desiccation of stratified muddy sediment and found that in the absence of surface 564 defects, crack origins are consistently located at or near the bottom of the polygons. During 565 drying, cracks initiated at the bottom and propagated vertically upward and laterally towards 566 adjacent cracks. The crack propagation from the bottom to the full depth was also observed by 567 Costa et al. [57] while testing desiccation cracking on three potato starch specimens. 
In this study, a desiccation cracking experiment was simulated using a hydro-mechanical model where (i) hydraulic diffusion under evaporation, (ii) the shrinkage of a soil sample and (iii) the initiation and propagation of desiccation cracks, among others couplings, were considered. The diffusion equation included the evolution of the soil and crack hydraulic 573 properties (degree of saturation, soil hydraulic conductivity and crack hydraulic conductivity, 574 the mass exchange between soil matrix/cracks), and the deformation processes of the soil and 575 the crack were equally taken into account. Finite element method code, including cohesive 576 fractures model, was used to simulate the development of cracks. The coupling between the 577 hydraulic and mechanical phenomena was performed through an iterative process passing 578 from the hydraulic problem resolution to the mechanical problem resolution and vice versa.

579 Cohesive cracks were embedded into the model to simulate potential cracks. By including a 580 large number of joint elements in the mesh, the model enables the detection of crack 581 development during drying. The results of the numerical simulation show good agreement with 582 the experimental data in terms of hydraulic diffusion, crack initiation, shrinkage evolution and 583 the chronology of desiccation phases (settlement without cracking and the formation and 584 propagation of cracks). The present work highlighted the importance of boundary conditions 585 when studying desiccation cracking. The simulation of a desiccation test revealed that cracks 586 could develop, in some cases from near the bottom of the specimen, and propagate towards the 587 top surface, even if the water evaporation occurs only from the top. The results of the present 588 work indicate that the proposed hydro-mechanical coupled model using the cohesive fracture 589 law for modelling crack propagation can accurately reproduce the hydro-mechanical coupled 590 phenomena related to shrinkage and crack formation during drying of clayey soil.

\section{Acknowledgement}


593 for their valuables comments.

\section{References}

[1] E. M. Kindle, "Some Factors Affecting the Development of Mud-Cracks," J. Geol., vol. 25, no. 2, pp. 135-144, 1917.

[2] J. T. K. Lau, "Desiccation cracking of soils," 1987.

[3] A. N. Abu-Hejleh and D. Znidarcic, "Desiccation Theory for Soft Cohesive Soils," J. Geotech. Eng., vol. 121, no. June, pp. 493-502, 1995.

[4] Towner, "The Mechanics of Cracking of Drying," J. agric. Engng Res, vol. 36, pp. 115-124, 1987.

[5] H. Peron, T. Hueckel, L. Laloui, and L. B. Hu, "Fundamentals of desiccation cracking of fine- grained soils : experimental characterisation and mechanisms identification," Can. Geotech. J., vol. 46, pp. 1177-1201, 2009.

[6] J. Kodikara and S. Costa, "Desiccation Cracking in Clayey Soils: Mechanisms and Modelling," Multiphysical Test. Soils Shales, pp. 21-32, 2013.

[7] R. Baker, "Tensile strength, tension cracks, and stability of slopes," Soils Found., vol. 21, no. 2, pp. 1-17, 1981.

[8] N. Yesiller, C. J. Miller, G. Inci, and K. Yaldo, "Desiccation and cracking behavior of three compacted landfill liner soils," Eng. Geol., vol. 57, pp. 105-121, 2000.

[9] G.H.Omidi, J.C.Thomas, and K.W.Brown, "Effect of desiccation cracking on the hydraulic conductivity of a compacted clay liner," Water. Air. Soil Pollut., vol. 89, pp. 91-103, 1996.

[10] J. K. Kodikara, S. L. Barbour, and D. G. Fredlund, "Desiccation cracking of soil layers," in UNSAT ASIA 2000, 2000, pp. 693-698.

[11] M. Sanchez, A. Atique, S. Kim, E. Romero, and M. Zielinski, "Exploring desiccation cracks in soils using a 2D profile laser device," Acta Geotech., vol. 8, no. 6, pp. 583596, Oct. 2013.

[12] C.-S. Tang, B. Shi, C. Liu, W.-B. Suo, and L. Gao, "Experimental characterization of shrinkage and desiccation cracking in thin clay layer," Appl. Clay Sci., vol. 52, pp. 6977, Apr. 2011.

[13] J. H. . Li and L. M. Zhang, "Study of desiccation crack initiation and development at ground surface," Eng. Geol., vol. 123, pp. 347-358, 2011. 
[14] J.-M. Konrad and R. Ayad, "Desiccation of a sensitive clay: field experimental observations," Can. Geotech. J., vol. 34, pp. 929-942, 1997.

[15] A. H. Lachenbruch, "Depth and spacing of tension cracks," J. Geophys. Res., vol. 66, no. 12, p. 4273, 1961.

[16] P. H.Morris, J.Graham, and D. J.Williams, "Cracking in drying soil," Can.Geotech, vol. 29, pp. 263-277, 1991.

[17] D. . Fredlund and N. R. Morgenstern, "Constitutive relations for volume change in unsaturated soils," Can. Geotech.J., vol. 13, pp. 261-276, 1976.

[18] J.-M. Konrad and R. Ayad, "An idealized framework for the analysis of cohesive soils undergoing desiccation,” Can. Geotech. J., vol. 34, pp. 477-488, 1997.

[19] A. L. Amarasiri, J. K.Kodikara, and S. Costa, "Numerical modelling of desiccation cracking," Int. J. Numer. Anal. Methods Geomech., vol. 35, pp. 82-96, 2010.

[20] H. Peron, J. Y. Delenne, L. Laloui, and M. S. El Youssoufi, "Discrete element modelling of drying shrinkage and cracking of soils," Comput. Geotech., vol. 36, no. 1-2, pp. 61-69, Jan. 2009.

[21] J. Sima, M. Jiang, and C. Zhou, "Numerical simulation of desiccation cracking in a thin clay layer using 3D discrete element modeling," Comput. Geotech., vol. 56, pp. 168180, Mar. 2014.

[22] R. A. Stirling, "Multiphase Modelling of Desiccation Cracking in Compacted Soil," Newcastle University, 2014.

[23] V. Ferber, J.-C. Auriol, Y.-J. Cui, and J.-P. Magnan, "Wetting-induced volume changes in compacted silty clays and high-plasticity clays," Can. Geotech. J., vol. 45, no. 2, pp. 252-265, Feb. 2008.

[24] E. E. Alonso, J. Vaunat, and A. Gens, "Modelling the mechanical behaviour of expansive clays," Eng. Geol., vol. 54, no. 1-2, pp. 173-183, Sep. 1999.

[25] S. Hirobe and K. Oguni, "Coupling analysis of pattern formation in desiccation cracks," Comput. Methods Appl. Mech. Eng., May 2016.

[26] D. Asahina, J. E. Houseworth, J. T. Birkholzer, J. Rutqvist, and J. E. Bolander, "Hydro-mechanical model for wetting/drying and fracture development in geomaterials," Comput. Geosci., vol. 65, pp. 13-23, Apr. 2014.

[27] R. Rodriguez, M. Sanchez, A. Ledesma, and A. Lloret, "Experimental and numerical analysis of desiccation of a mining waste," Can. Geotech. J., vol. 658, pp. 644-658, 2007.

[28] H. Péron, L. . Hu, L. Laloui, and T. Hueckel, "Numerical and Experimental Investigation of Desiccation of Soil," no. 3, pp. 3-8, 2007. 
[29] O. P. Coussy and S. Brisard, "Prediction of drying shrinkage beyond the pore isodeformation assumption," J. Mech. Mater. Struct., vol. 4, no. February, pp. 263$279,2009$.

[30] M. Sánchez, O. L. Manzoli, and L. J. N. Guimarães, "Modeling 3-D desiccation soil crack networks using a mesh fragmentation technique," Comput. Geotech., vol. 62, pp. 27-39, Oct. 2014.

[31] A. L. Amarasiri and J. K. Kodikara, "Numerical Modeling of Desiccation Cracking Using the Cohesive Crack Method," Int. J. Geomech., vol. 13, pp. 213-221, 2013.

[32] A. Pouya and P. Bemani, "A damage-plasticity model for cohesive fractures," Int. J. Rock Mech. Min. Sci., vol. 73, pp. 194-202, 2015.

[33] A. Pouya, "A finite element method for medeling coupled flow and deformation in porous fractured media," Int. J. Numer. Anal. Methods Geomech., vol. 32, 2015.

[34] A. Pouya, T. D. Vo, S. Hemmati, and V. L. Nguyen, "Modélisation numérique de la fissuration hydrique d'un sol non saturé," in SEC2015, 2015, pp. 1-10.

[35] R. E. Goodman, Methods of Geological Engineering in Discontinuous Rocks. 1976, p. 484.

[36] M. T. van Genuchten, "A Closed-form Equation for Predicting the Hydraulic Conductivity of Unsaturated Soils1," Soil Sci. Soc. Am. J., vol. 44, p. 8, 1980.

[37] L. a. Richards, "Capillary Conduction of Liquids Through Porous Mediums," Physics (College. Park. Md)., vol. 1, no. 5, p. 318, 1931.

[38] R. W. Zimmerman and G. S. Bodvarsson, "Hydraulic Conductivity of Rock Fractures," 1994.

[39] G. El Mountassir, M. Sánchez, E. Romero, and R. a a Soemitro, "Behaviour of compacted silt used to construct flood embankment," Proc. ICE - Geotech. Eng., vol. 164, no. 3, pp. 195-210, Jun. 2011.

[40] G. El Mountassir, M. Sánchez, and E. Romero, "An experimental study on the compaction and collapsible behaviour of a flood defence embankment fill," Eng. Geol., vol. 179, pp. 132-145, Sep. 2014.

[41] G.Mesri and Y.K.Choi, "Settlement of Embankments on Soft Clays," J. Geotech. Geoenvironmental Eng., vol. 111, no. 4, pp. 441-464, 1985.

[42] A. L. Amarasiri, S. Costa, and J. K. Kodikara, "Determination of cohesive properties for mode I fracture from compacted clay beams," Can. Geotech. J., vol. 38, pp. 11631173, 2011.

[43] H. Shin and J. C. Santamarina, "Desiccation cracks in saturated fine-grained soils : particle-level phenomena and effective-stress analysis," Géotechnique, vol. 61, no. 11, pp. 961-972, 2011. 
695

696

697

698

699

700

701

702

703

704

705

706

707

708

709

710

711

712

713

714

715

716

717

718

719

720

721

722

723

724
[44] T. Backers, "Fracture Toughness Determination and Micromechanics of Rock Under Mode I and Mode II Loading," 2004.

[45] G. W. Wilson, "Soil Evaporative Fluxes for Geotechnical Engineering Problems," 1990.

[46] G. W. Wilson, D. G. Fredlund, and S. L. Barbour, "Coupled soil-atmosphere modelling for soil evaporation," Can. Geotech. J., vol. 31, no. 2, pp. 151-161, Apr. 1994.

[47] W. Song, Y. Cui, A. M. Tang, W. Ding, and T. D. Tran, "Experimental study on water evaporation from sand using environmental chamber," Can.Geotech, vol. 51, pp. 115$128,2014$.

[48] W.-K. Song, Y.-J. Cui, A. M. Tang, W.-Q. Ding, and Q. Wang, "Experimental study on water evaporation from compacted clay using environmental chamber," Can.Geotech, pp. 1-12, 2016.

[49] G. W. Wilson, D. G. Fredlund, and S. L. Barbour, "The effect of soil suction on evaporative fluxes from soil surfaces," Can.Geotech, no. 1990, 1997.

[50] H. M. Westergaard, "Bearing pressure and cracks," J. Appl. Mech., pp. 49-53, 1939.

[51] T.-H. Kim and C. Hwang, "Modeling of tensile strength on moist granular earth material at low water content," Eng. Geol., vol. 69, no. 3-4, pp. 233-244, Jun. 2003.

[52] G. D. Towner, "The Tensile Stress Generated in Clay through Drying," J. agric. Engng Res, vol. 37, pp. 279-289, 1987.

[53] H. Peron, L. Laloui, T. Hueckel, and L. B. Hu, "Desiccation cracking of soils," Fail. Multiph. geomaterials, vol. 13, pp. 869-888, Aug. 2009.

[54] H. Nahlawi and J. K. Kodikara, "Laboratory experiments on desiccation cracking of thin soil layers," Geotech. Geol. Eng., vol. 24, no. 6, pp. 1641-1664, Dec. 2006.

[55] S. Costa and J. Kodikara, "Evaluation of J Integral for Clay Soils Using a New Ring Test," Geotech. Test. Journalournal, vol. 35, no. 6, pp. 981-989, 2012.

[56] R. Weinberger, "Initiation and growth of cracks during desiccation of stratified muddy sediments," J. Struct. Geol., vol. 21, pp. 379-386, 1999.

[57] S. Costa, J. Kodikara, and B. Shannon, "Salient factors controlling desiccation cracking of clay in laboratory experiments," Géotechnique, vol. 63, no. 1, pp. 18-29, Jan. 2013. 

Figure 3: Compression curve obtained from oedometer test (Experimental data taken from [40])

$730 \quad$ Figure 4: Geometry and boundary condition .................................................................... 34

731 Figure 5: (a) Evaporation rate versus degree of saturation and (b) Evaporation rate versus

732 suction (Experimental data taken from [11])

733 Figure 6: (a) Description of the cracks observed at various moments and (b) Distribution of

735 Figure $7:$ (a) Suction and (b) Degree of saturation versus elapsed time. (Experimental data taken from [11])

Figure 8: Scheme showing the different components of soil shrinkage

739 Figure 10: Isochrones of: (a) Normal stress, (b) Damage variable and (b) Opening of joint

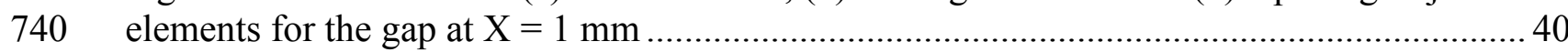

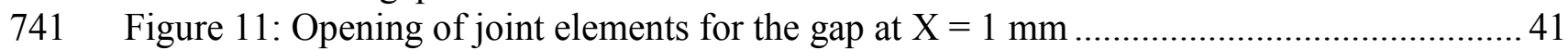

742 Figure 12 : Isochrones of: (a) Normal stress, (b) Damage variable and (b) Opening of joint elements for the crack at $\mathrm{X}=35 \mathrm{~mm}$

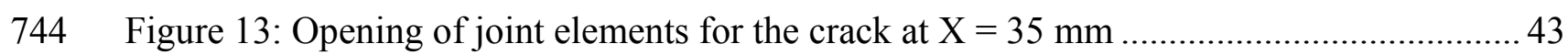

745 Figure 14: Cracks position and normal stress of a half left specimen on the top surface ....... 44

746 Figure 15: Evolution of normal stress of the crack at $X=35 \mathrm{~mm}$..........................................4 45

\section{List of Tables:}

749 Table 1: Parameters of soil and cohesive cracks. 


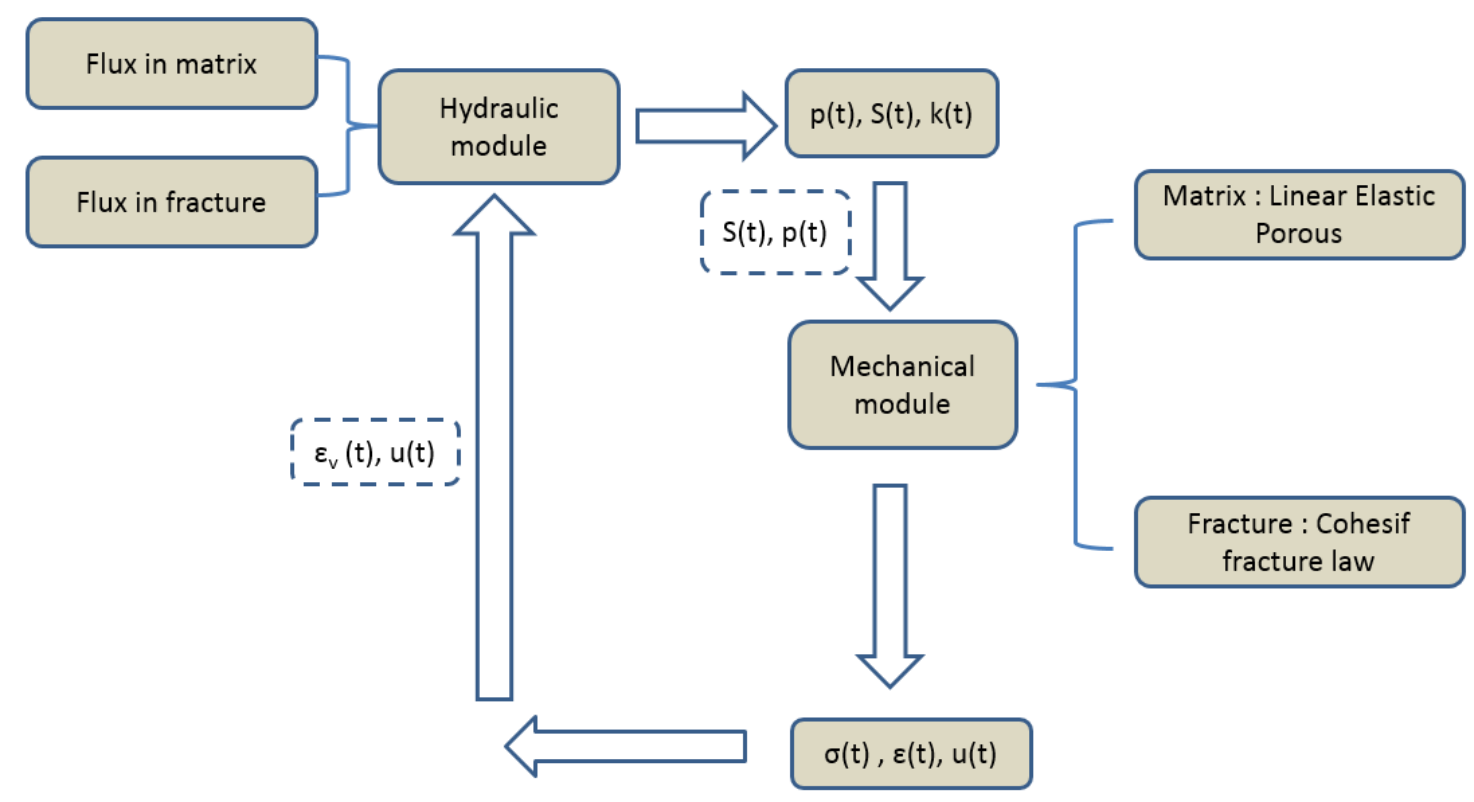

Figure 1: Scheme of the hydro-mechanical coupling 


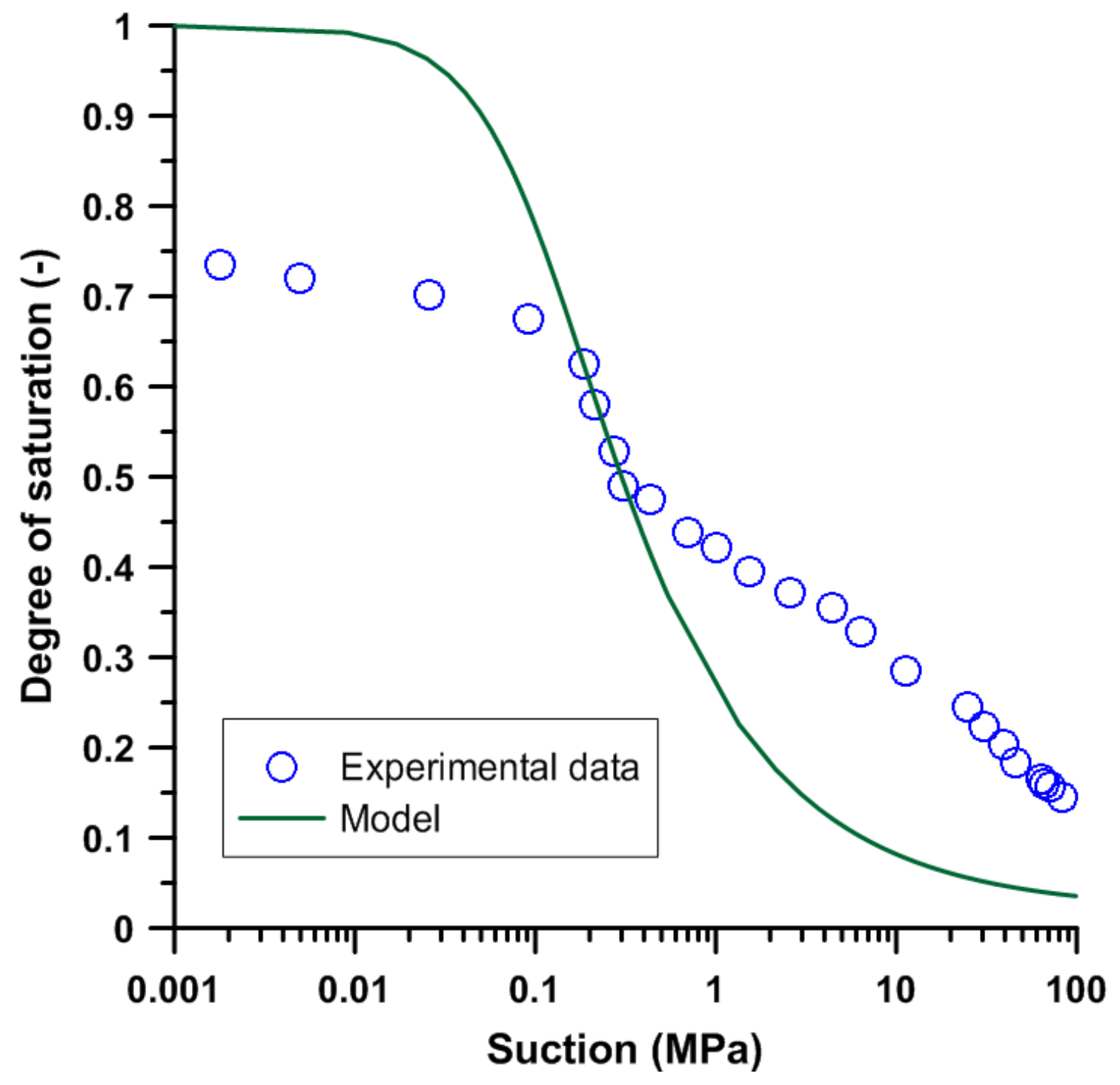

Figure 2: Water retention curve (Experimental data taken from [39])

775

776

777

778

779

780

781

782

783

784

785

786

787

788

789 


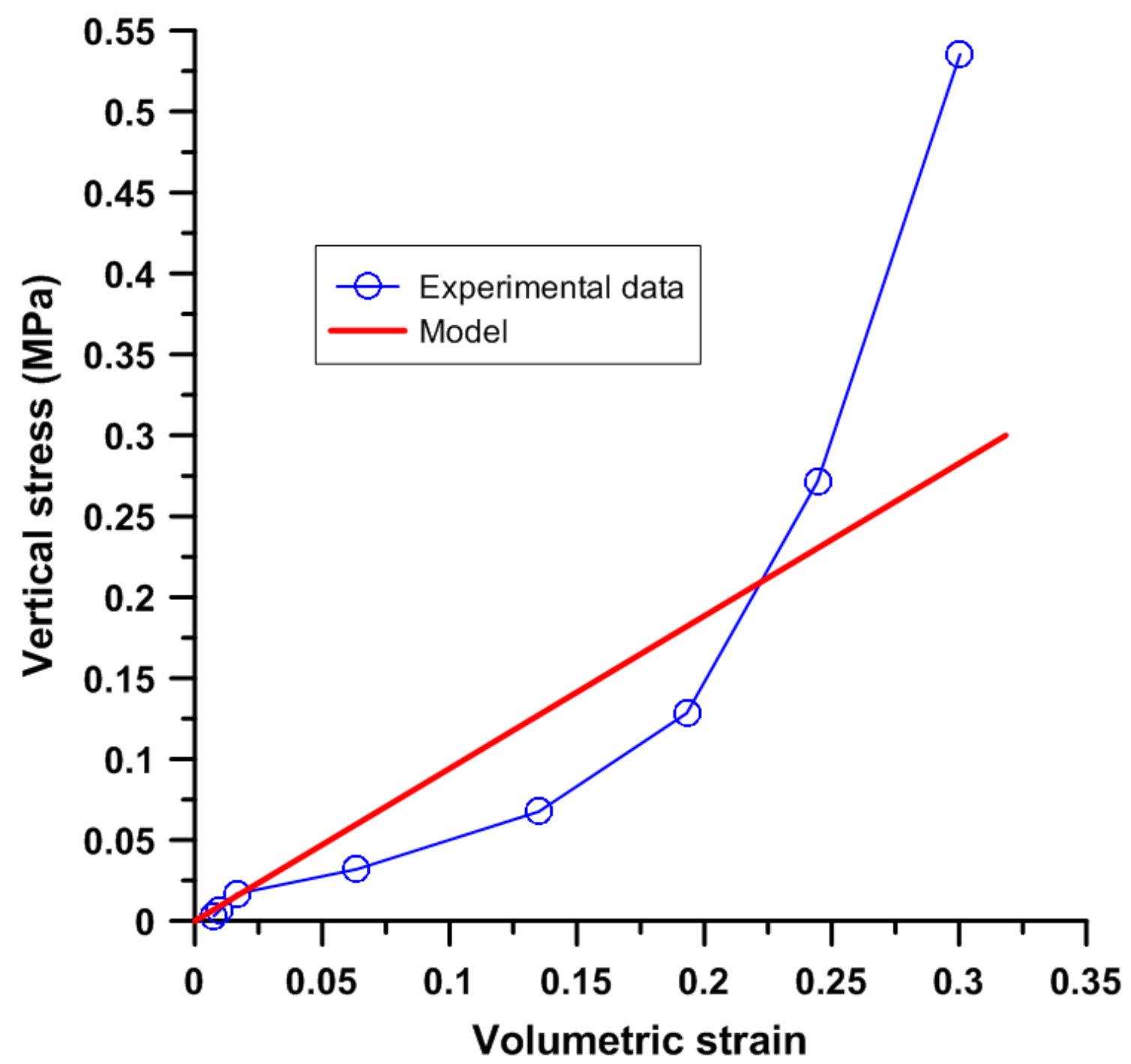

Figure 3: Compression curve obtained from oedometer test (Experimental data taken from [40]) 


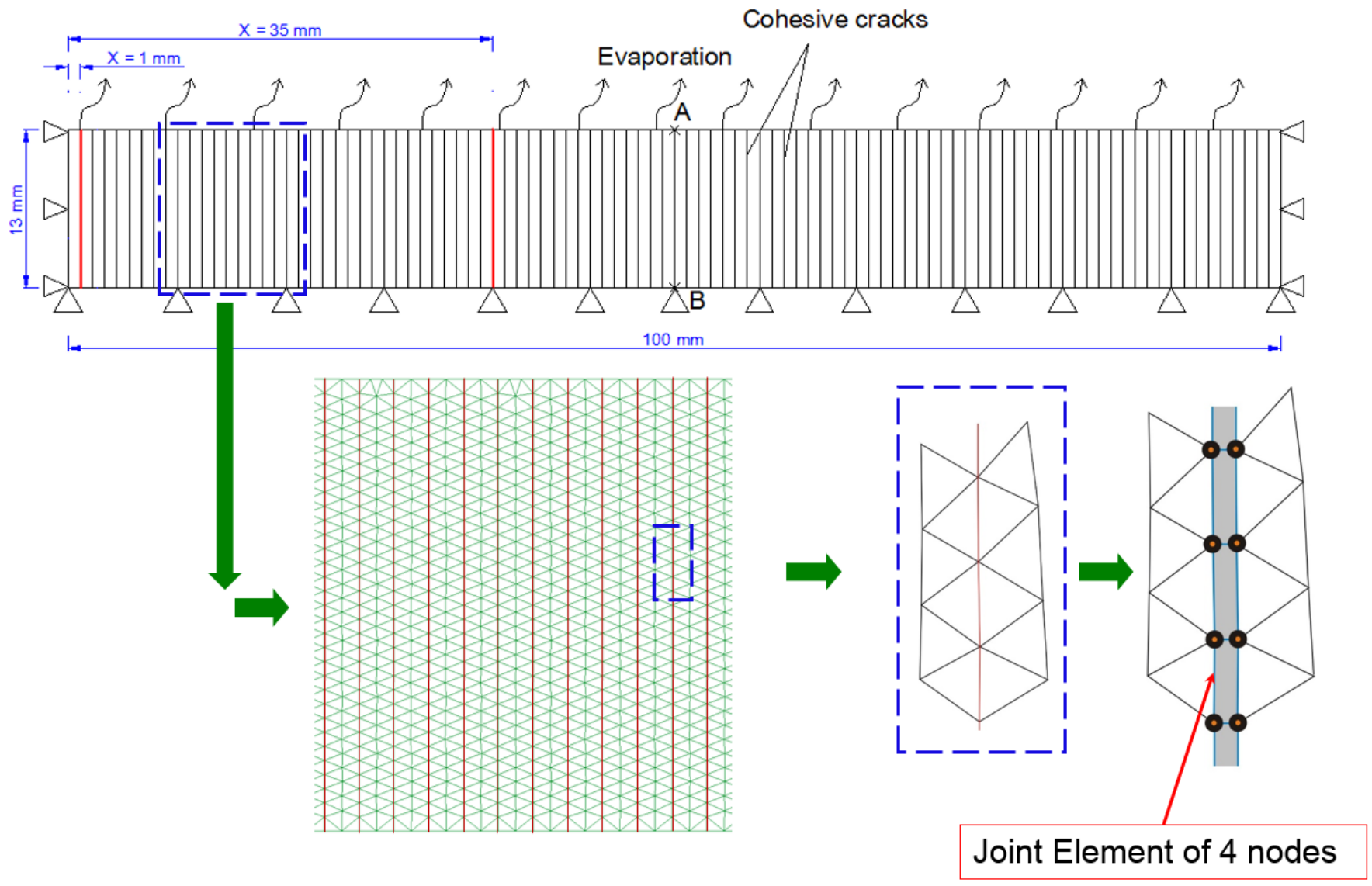

Figure 4: Geometry and boundary condition 

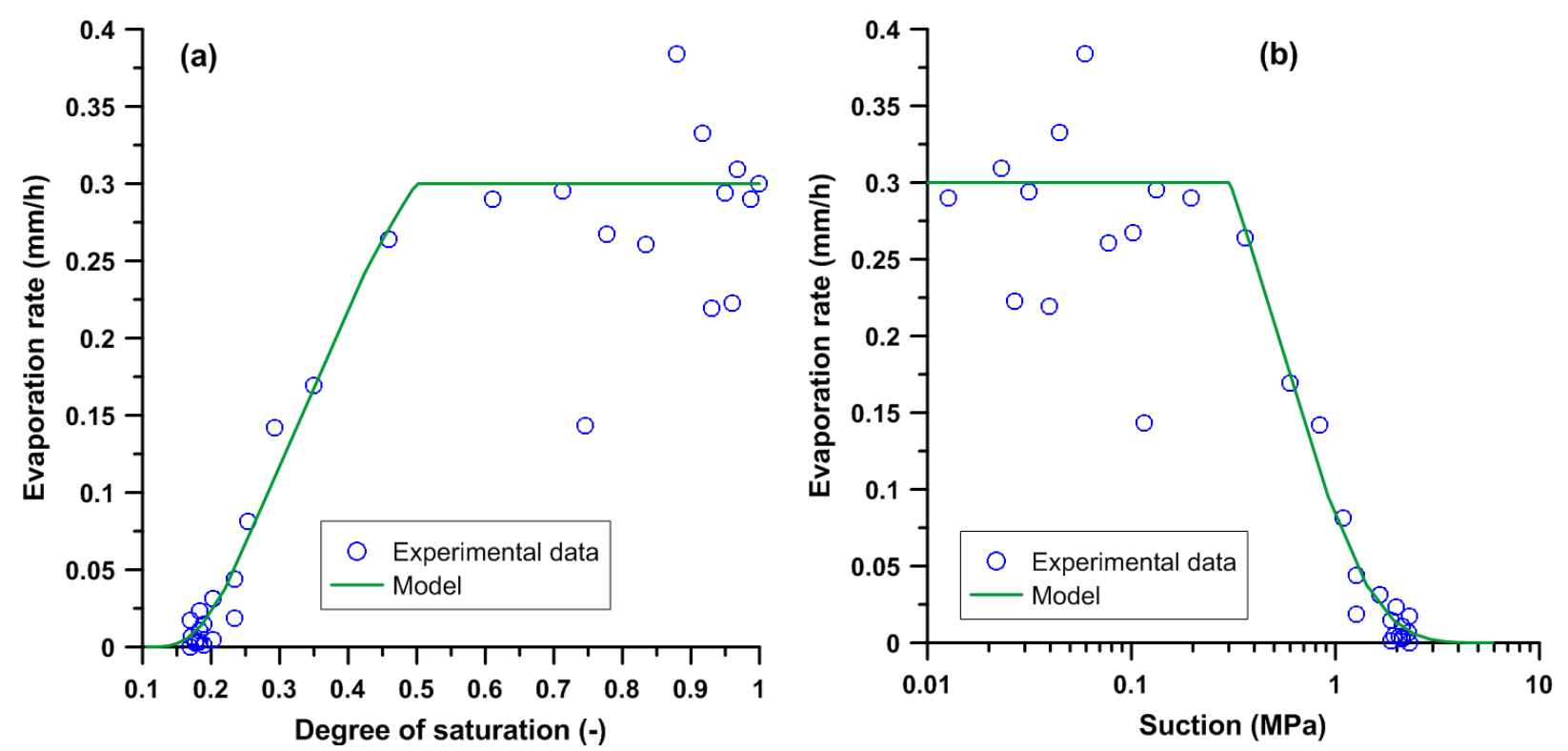

Figure 5: (a) Evaporation rate versus degree of saturation and (b) Evaporation rate versus 

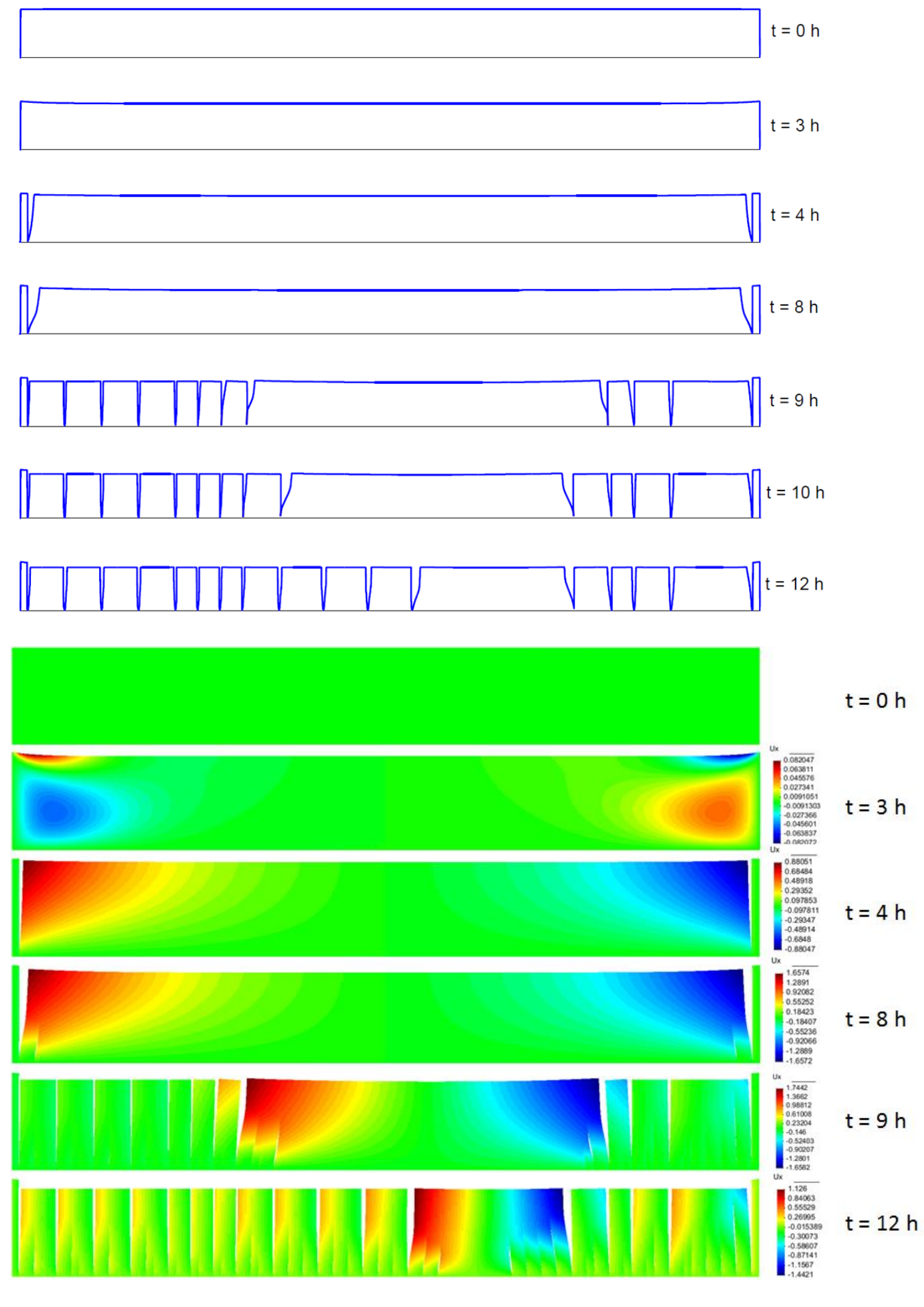

Figure 6: (a) Description of the cracks observed at various moments and (b) Distribution of 861 horizontal displacement 
873
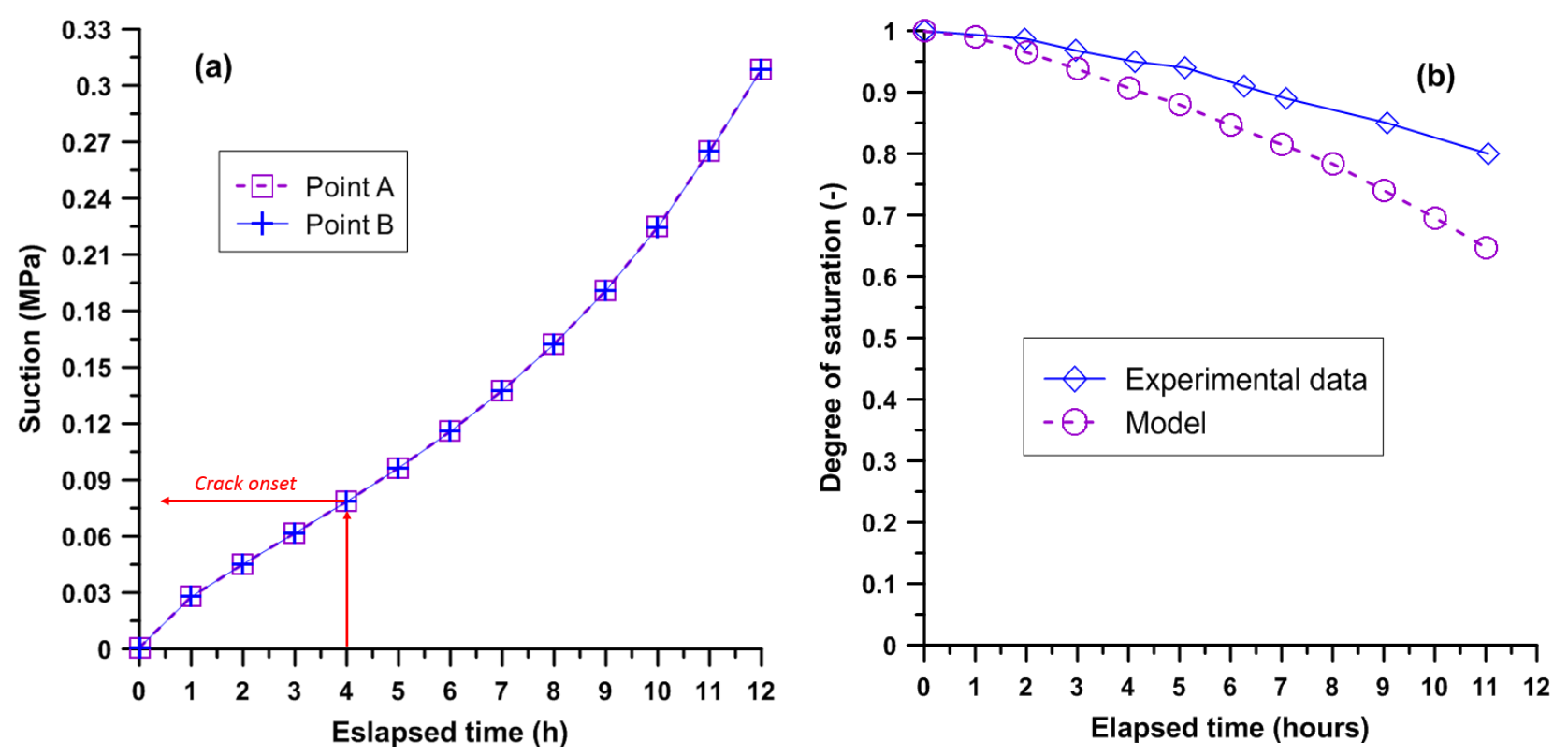

875

876

877

Figure 7 : (a) Suction and (b) Degree of saturation versus elapsed time. (Experimental data taken from [11])

878

879

880

881

882

883

884

885

886

887

888

889

890

891

892

893

894

895

896

897

898 


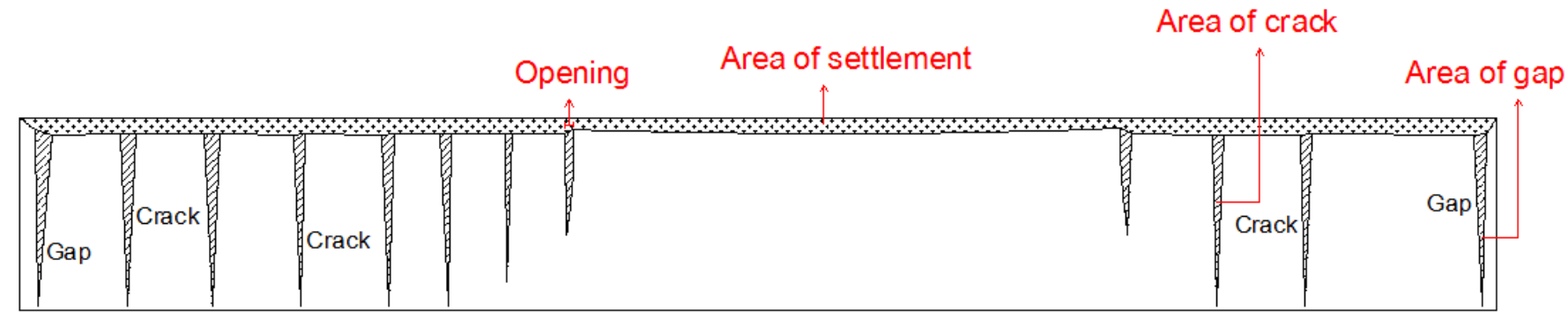

903

905

906

907

908

909

910

911

912

913

914

915

916

917

918

919

920

921

922

923

924

925

926

927

928

929 


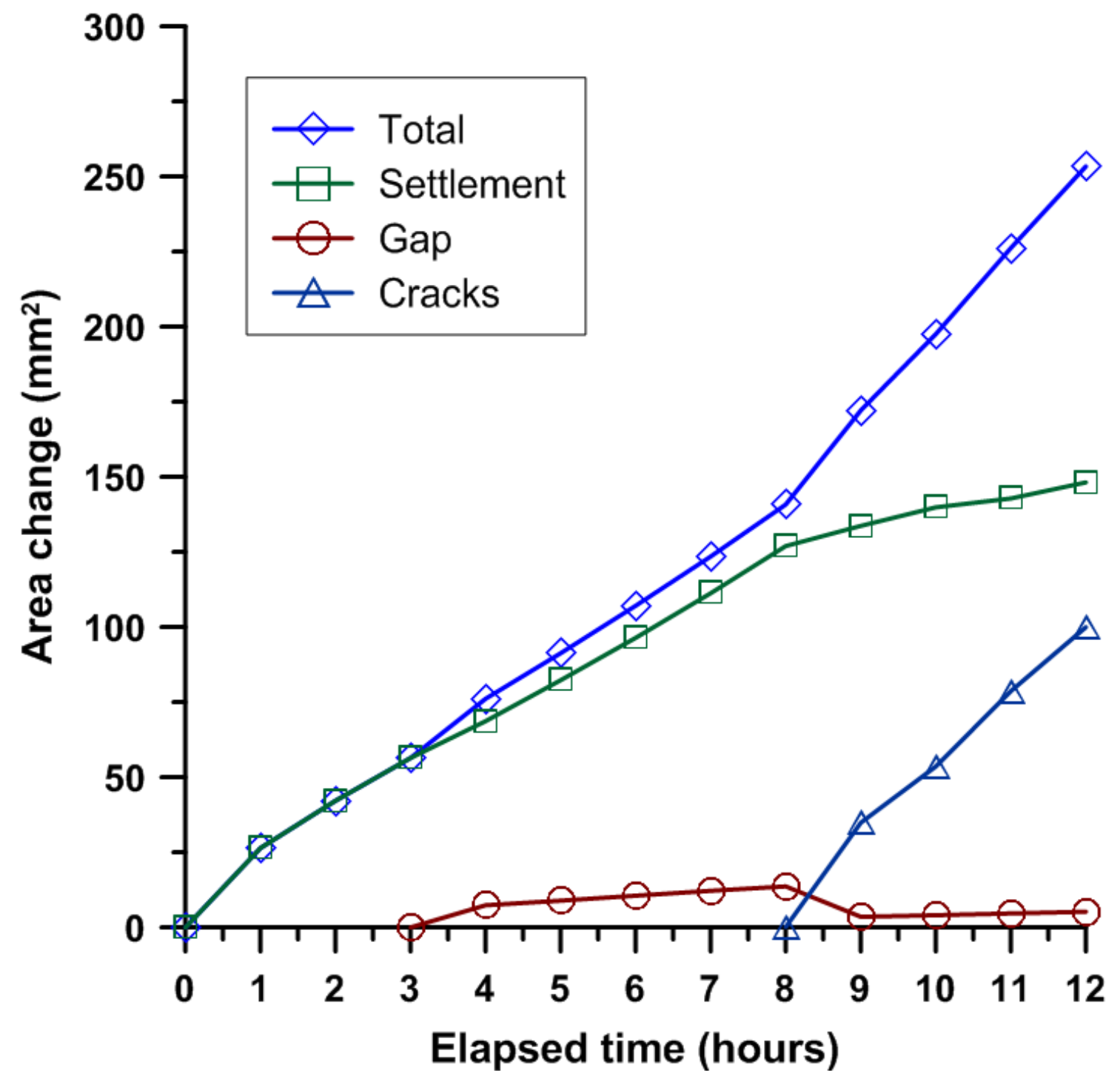

Figure 9 : Time evolution of different components of soil shrinkage

934

935

936

937 

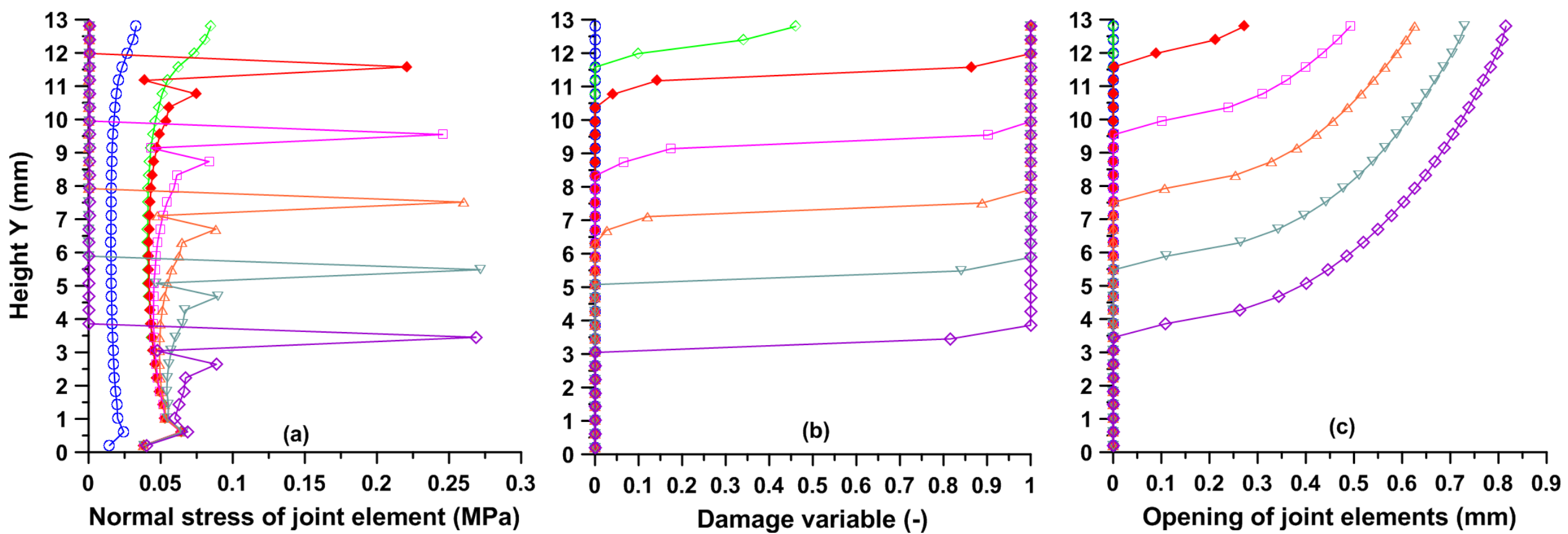

$$
\begin{aligned}
& \ominus \mathrm{t}=1.000 \mathrm{~h} \square \mathrm{t}=3.515 \mathrm{~h} \nabla \mathrm{t}=3.525 \mathrm{~h} \\
& \checkmark \mathrm{t}=3.505 \mathrm{~h} \triangle \mathrm{t}=3.520 \mathrm{~h} \triangleleft \mathrm{t}=3.530 \mathrm{~h} \\
& \neg \mathrm{t}=3.510 \mathrm{~h}
\end{aligned}
$$

Figure 10: Isochrones of: (a) Normal stress, (b) Damage variable and (b) Opening of joint elements for the gap at $\mathrm{X}=1 \mathrm{~mm}$ 


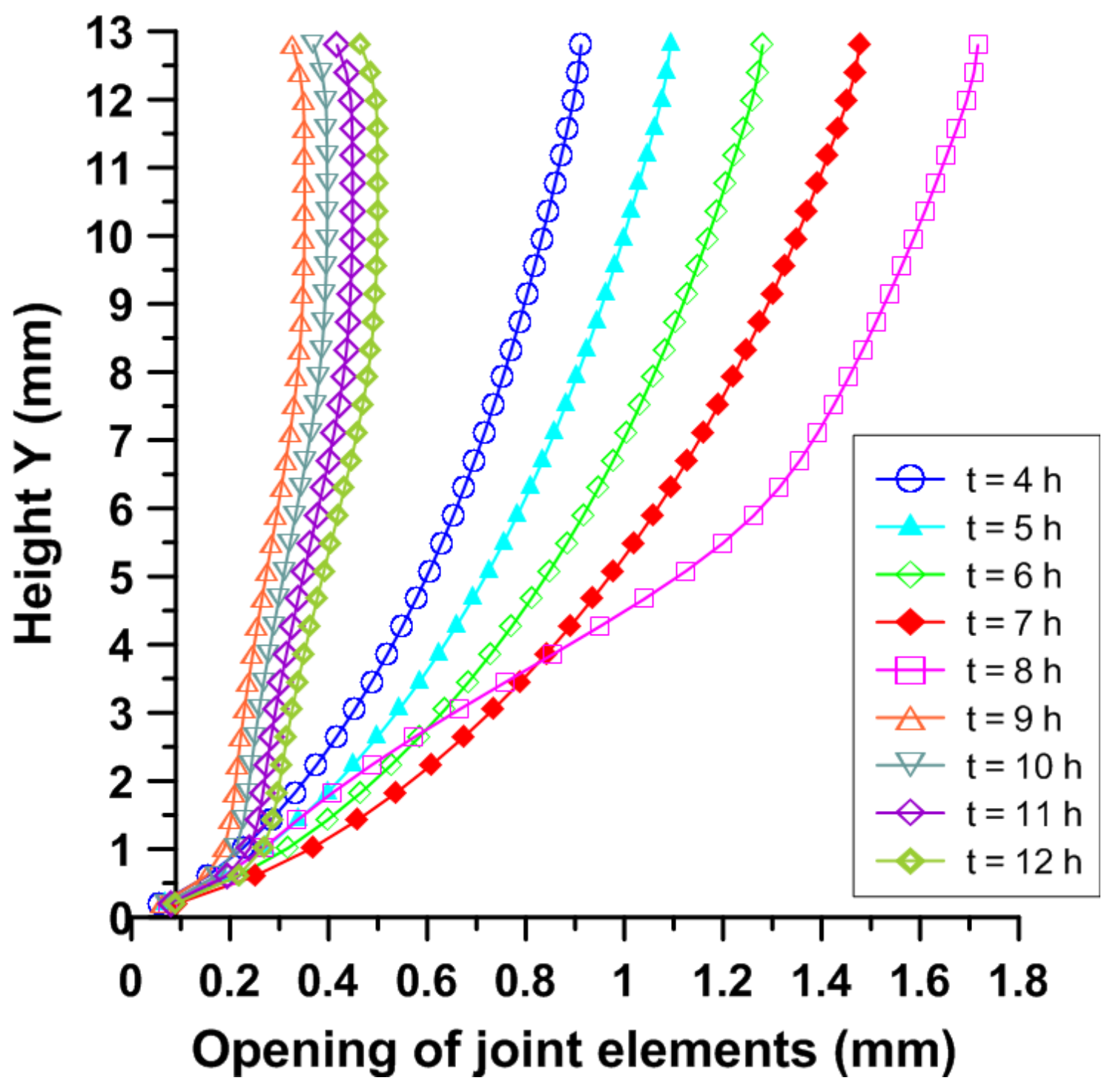

945

946

947

948

949

Figure 11: Opening of joint elements for the gap at $\mathrm{X}=1 \mathrm{~mm}$ 
950
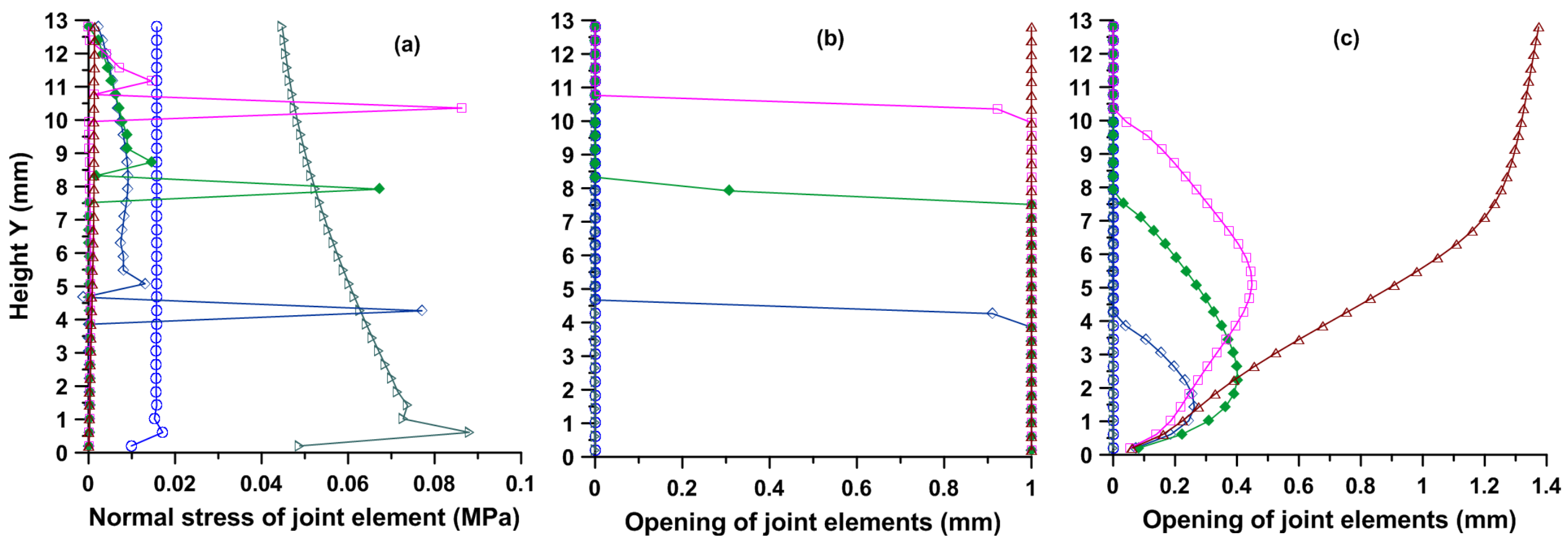

$$
\begin{aligned}
& \ominus \mathrm{t}=1.00 \mathrm{~h} \smile \mathrm{t}=8.95 \mathrm{~h} \square \mathrm{t}=9.05 \mathrm{~h} \\
& \diamond \mathrm{t}=8.50 \mathrm{~h} \smile \mathrm{t}=9.00 \mathrm{~h} \triangle \mathrm{t}=9.10 \mathrm{~h}
\end{aligned}
$$




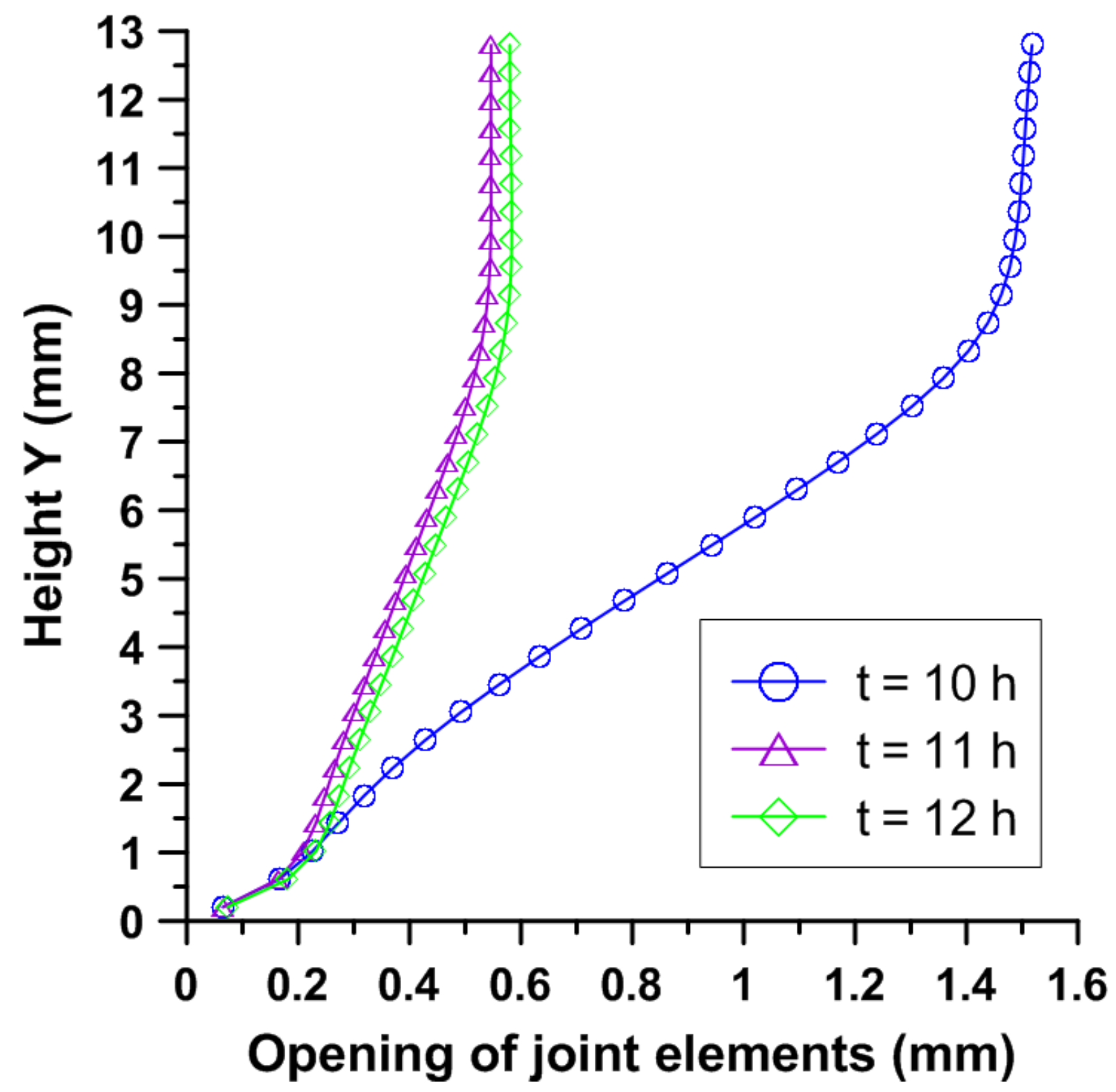



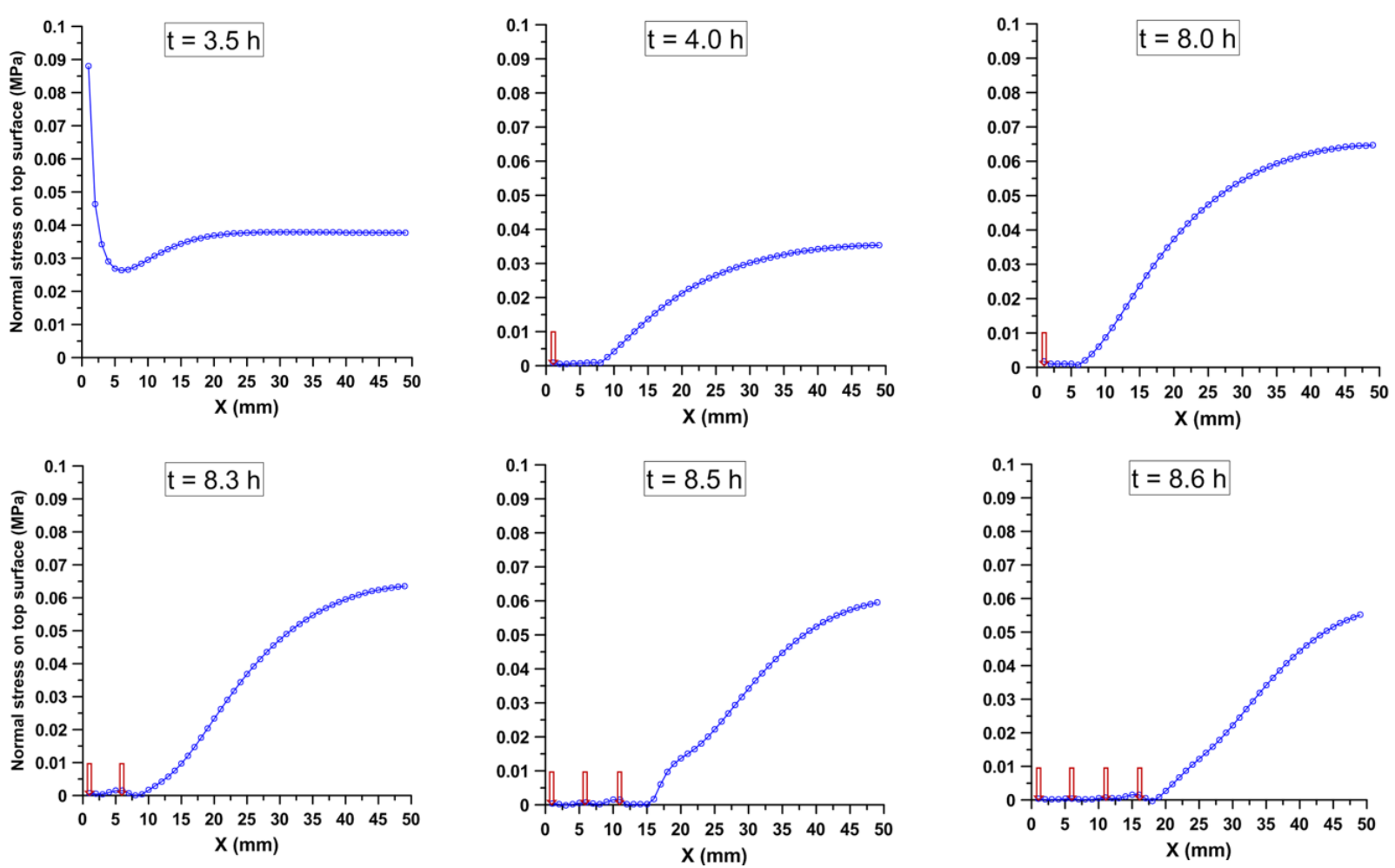

Figure 14 : Cracks position and normal stress of a half left specimen on the top surface 


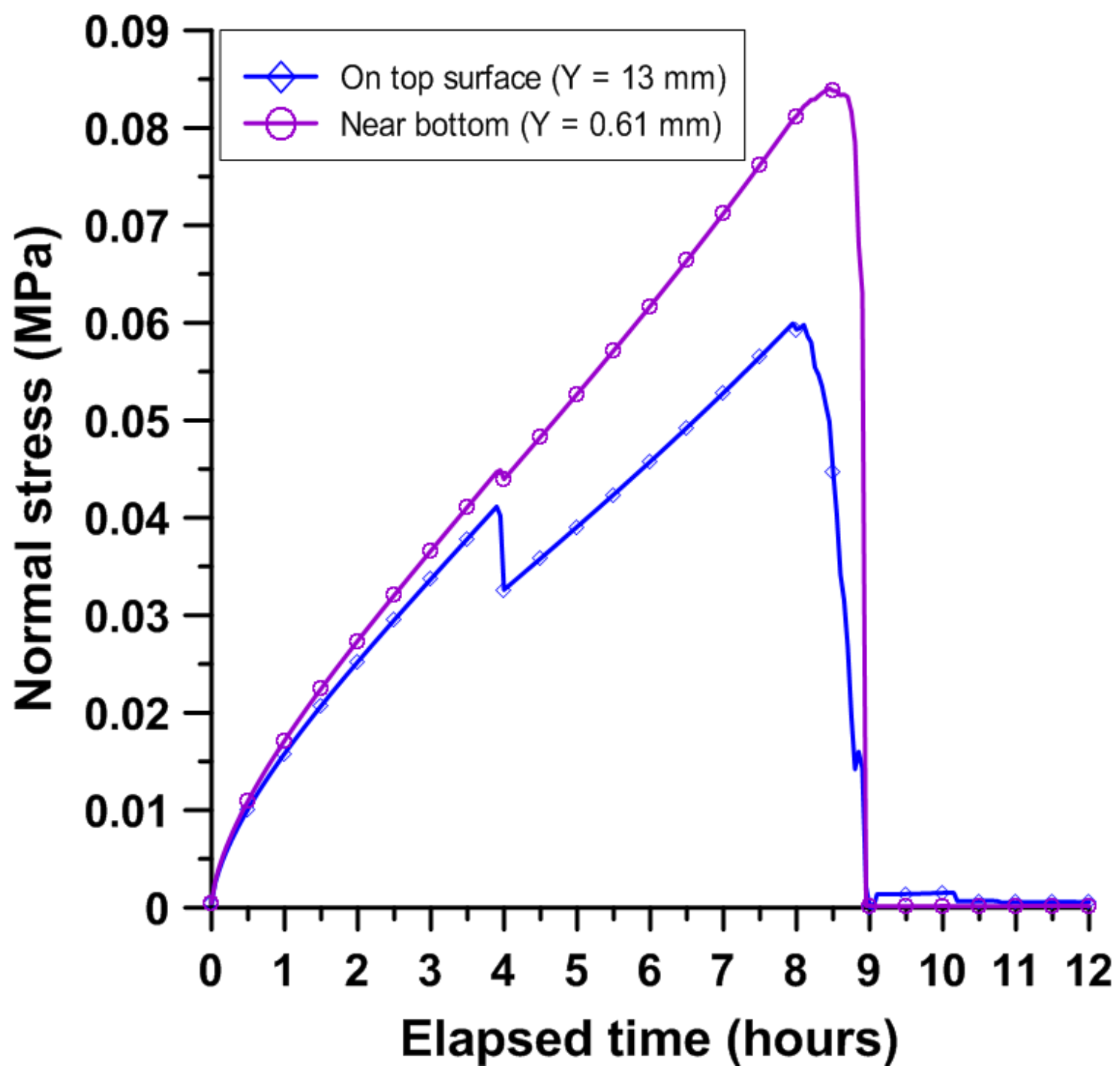

Figure 15: Evolution of normal stress of the crack at $X=35 \mathrm{~mm}$

972
973

974

975

976

977

978

979

980

981

982

983

984

985

986

987

988

989

990 


\begin{tabular}{|c|c|c|c|c|c|c|c|c|}
\hline \multirow{3}{*}{ Soil } & $E$ & $v$ & $k_{s}$ & $\phi$ & $\alpha$ & $n$ & $m$ & $S_{r}$ \\
& $(\mathrm{MPa})$ & $(-)$ & $(\mathrm{m} / \mathrm{s})$ & $(-)$ & $\left(\mathrm{MPa}^{-1}\right)$ & $(-)$ & $(-)$ & $(-)$ \\
\cline { 2 - 9 } & 1 & 0.3 & $10^{-8}$ & 0.60 & 9.81 & 1.60 & 0.375 & 0.02 \\
\hline
\end{tabular}

991

992

993

994

995

996

997

998

999

\begin{tabular}{|c|c|c|c|c|c|c|c|c|}
\hline \multirow{2}{*}{ Cracks } & $R_{t t}$ & $R_{n n}$ & $R_{t n}=R_{n t}$ & $\sigma_{R}$ & $C_{\text {coh }}$ & $\varphi$ & $\beta$ & $e_{0}$ \\
\cline { 2 - 9 } & $(\mathrm{MPa} / \mathrm{mm})$ & $(\mathrm{MPa} / \mathrm{mm})$ & $(\mathrm{MPa} / \mathrm{mm})$ & $(\mathrm{MPa})$ & $(\mathrm{MPa})$ & $\left(^{\circ}\right)$ & $(-)$ & $(\mathrm{mm})$ \\
\hline
\end{tabular}

Table 1: Parameters of soil and cohesive cracks. 